\title{
The Role of Substrate-Coenzyme Crosstalk in Determining Turnover Rates in Rhodococcus ruber Alcohol Dehydrogenase
}

\author{
Thilak Reddy Enugala, Marina Corbella Morató, Shina C. L. Kamerlin,* and Mikael Widersten* \\ Cite This: ACS Catal. 2020, 10, 9115-9128 \\ Read Online
}

ABSTRACT: Eight related alcohol dehydrogenases, which had been originally isolated by laboratory evolution of $\mathrm{ADH}-\mathrm{A}$ from Rhodococcus ruber DSM44541 for modified substrate scopes, were together with their parent wild-type subjected to biochemical characterization of possible activities with a panel of chiral alcohols and pro-chiral ketones. Determinations of rates of catalyzed alcohol oxidations and ketone reductions, and of cofactor release, pointed out to the role of a W295A substitution as being decisive in steering enantioselectivity in the oxidation of arylated 1-methyl substituted alcohols. Molecular dynamics simulations of enzyme-substrate interactions in the Michaelis complexes of wild-type $\mathrm{ADH}-\mathrm{A}$ and a Y294F/W295A double mutant could rationalize the

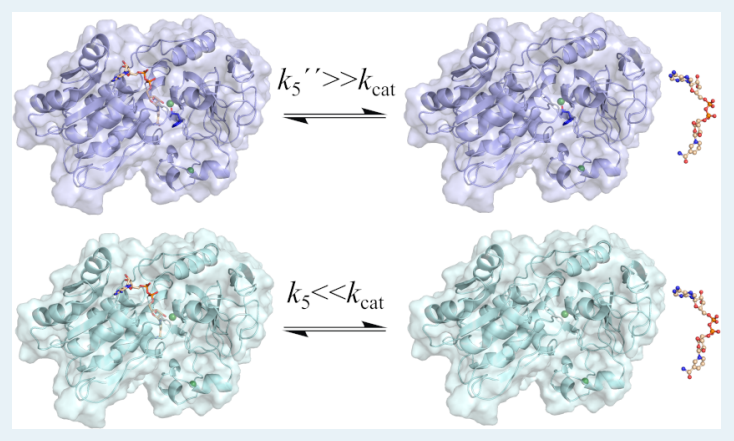
experimentally observed shift in enantioselectivity and differences in catalytic activity with 4-phenyl-2-butanol. Finally, we present herein evidence for apparent interdependency between substrate/ product and the cofactor in the ternary complex, which directly affects the NADH dissociation rates; therefore, this substratecoenzyme crosstalk plays a direct role in determining the turnover rates.

KEYWORDS: alcohol dehydrogenase, substrate selectivity, active-site structure, stereoselectivity, molecular dynamics simulations

\section{INTRODUCTION}

The laboratory evolution of proteins ${ }^{1,2}$ has opened up new possibilities for studies of structure-activity relationships, ${ }^{3}$ the emergence of novel functional properties, ${ }^{4-6}$ and the development of new biomolecular tools such as biocatalysts ${ }^{7-10}$ or binding proteins. ${ }^{11,12} \mathrm{New}$ catalytic properties in enzymes may arise as a consequence of the improvement of a (hidden) promiscuous activity, which becomes unveiled following mutagenesis events. In order for a new property to penetrate and contribute to a more beneficial phenotype, it is believed that a preceding duplication of the gene for the native enzyme is necessary, thus relieving the negative selective pressure of functional divergence from the native state ${ }^{13,14}$ The presence of promiscuous functions appears to be a common, if not even general, feature in enzymes, ${ }^{15-22}$ and the concept appears to be applicable also to in vitro-evolved enzymes (see ref 23 for a recent example).

Chiral alcohols are among the most abundant synthetic building blocks in the production of pharmaceuticals, chiral auxiliaries, and natural products. $\mathrm{NAD}(\mathrm{P})$ dependent alcohol dehydrogenases (E.C. 1.1.1.1) are important biocatalysts for producing optically pure chiral alcohols either by kinetic resolution from oxidation of racemic alcohol mixtures or enantioselective reduction of the corresponding ketones. ${ }^{24-26}$ The limitation of coenzyme regeneration, which is a requirement for using these enzymes for synthesis at any practical scale, can be addressed by various strategies employing cheap sacrificial alcohols, such as isopropanol; whole-cell systems; or coupled enzyme cascade reactions. ${ }^{27-34}$

We have previously studied and engineered alcohol dehydrogenase A (ADH-A) from Rhodococcus ruber DSM $44541^{34-37}$ (Figure 1) for the purpose of generating new enzyme forms with predesigned catalytic properties regarding substrate scope and selectivity. ${ }^{38-40}$

The goal of this work was to test for possible intrinsic substrate promiscuities arising as a consequence of the structural alternations introduced into the enzyme variants summarized in Table 1 . In addition, we aimed to assess the biocatalytic potential of resolved alcohol oxidation and stereoselective ketone reduction of a spectrum of putative substrates (Scheme 1). To achieve this, the enzymes were biochemically characterized with respect to their activities during both the steady- and presteadystate phases of the catalyzed reactions, determining rate constants for turnover, alcohol oxidation, and $\mathrm{NADH}$ association and dissociation together with the equilibrium dissociation constants of alcohols and NADH. The reaction products were further analyzed for their stereoconfigurations. In

Received: April 12, 2020

Revised: July 14, 2020

Published: July 16, 2020 
A
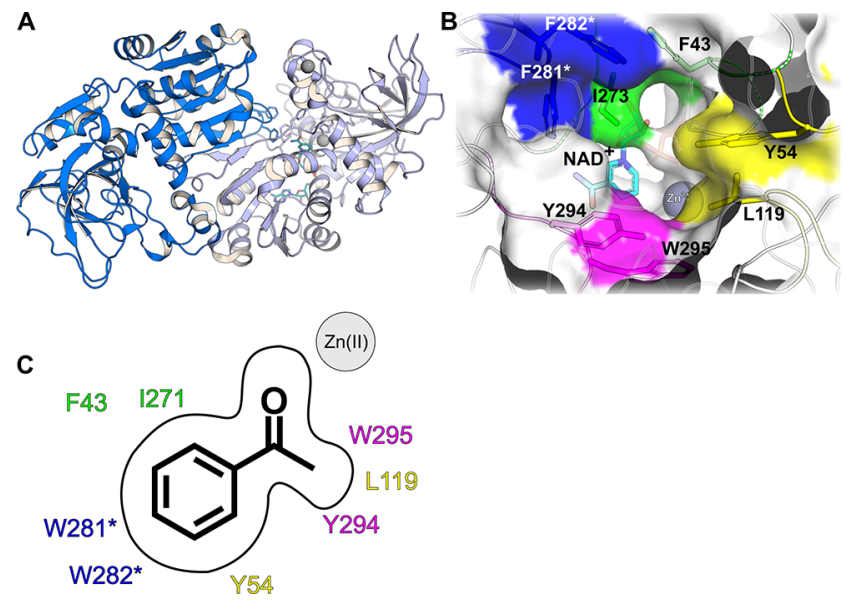

Figure 1. (A) Dimeric structure of wild-type ADH-A, shown in ribbon representation. The residues that have been substituted in the different enzyme variants are shown in stick representation in one subunit, together with the cofactor $\mathrm{NAD}^{+}$. The two essential zinc ions are shown as spheres. (B) Close-up of the ADH-A active site. The side chains of the substituted amino acid residues are shown as sticks and colored according to the different groupings of residues in the original CASTing procedure. ${ }^{41}$ The specific substitutions in different variants are shown in Table 1. The asterisk indicates residues from the neighboring subunit of the dimer. Both panels were created on the basis of the atomic coordinates in PDB ID: 3jv $7^{42}$ using PyMol 2.3. ${ }^{43}$ (C) Schematic description of residue contributions to the different subsites of the ketone/alcohol binding site.

addition, molecular dynamics simulations allowed us to explore different putative substrate binding modes in the $\mathrm{ADH}-\mathrm{A}$ variants studied here, as well as their likely impact on the observed $\mathrm{ADH}$-A selectivity. The results therefore enable us to identify residues critical for stereoselectivity in alcohol oxidation and ketone reduction.

\section{MATERIALS AND METHODS}

Structural Analysis. The volumes of the active site cavities of the $\mathrm{ADH}$-A variants considered in this work were analyzed by CASTp 3.0, ${ }^{45}$ using the CASTp online server (http://sts.bioe. uic.edu/castp/calculation.html). The analysis was specifically performed on PDB IDs: 3jv7 (wild-type ADH-A), 5o9d (A2C2B1 variant), 5o9f (A2C3 variant), 5od3 (B1 variant), $6 \mathrm{fg} 0$ (B1F4 variant), 6ffx (C1 variant), and 6ffz (C1B1 variant). ${ }^{38-40,42}$ The $\mathrm{A} 2$ variant crystallized into a different
Scheme 1. Different Alcohols and Ketones Studied in This Work<smiles>CCCC(O)c1ccccc1CC(O)CC(C)C(C)O</smiles><smiles>CC(=O)c1ccccc1</smiles><smiles>CCC(=O)c1ccccc1</smiles><smiles>CCCC(=O)c1ccccc1</smiles><smiles>CC(=O)CCc1ccccc1</smiles><smiles>CC(=O)Cc1ccccc1</smiles><smiles>CCC(=O)Cc1ccccc1</smiles><smiles>CC(C)=O</smiles>

space group $\left(P 2_{1} 2_{1} 2_{1}\right)$ as compared with all the other variants $\left(\mathrm{P} 2_{1}\right)$, and the asymmetric unit cell contained eight subunit chains rather than four. Therefore, to lower the computational cost of the analysis and to mimic the oligomeric state of the other proteins in the crystalline state, the coordinates file for the A2 variant (PDB ID: $508 \mathrm{q}^{38}$ ) was truncated to contain four subunit chains before analysis. The cavity volumes were accepted as provided by the CASTp server, and the average volumes with standard deviations of the four cavities per structure were calculated in each case.

Enzyme Expression and Purification. All proteins were produced, purified, and analyzed as described in previous work. $^{37-40}$

Steady-State Kinetics. Initial rates of $\mathrm{ADH}-\mathrm{A}$ catalyzed alcohol oxidation or ketone reduction were recorded as follows: (A) alcohol oxidation was assayed by measuring the formation of NADH at $340 \mathrm{~nm}\left(\varepsilon=6.22 \mathrm{mM}^{-1} \mathrm{~cm}^{-1}\right)$ in a spectrophotometer in a $1 \mathrm{~cm}$ cuvette. The reactions were measured in the presence of saturating concentrations of $\mathrm{NAD}^{+}$ $(1.6 \mathrm{mM})$ and varied alcohol (1-7) concentrations, in sodium phosphate buffer, $\mathrm{pH}$ 8.0, fortified with $10 \mu \mathrm{M} \mathrm{ZnSO}$. (B) Ketone reduction was measured under the same conditions, but in a $0.5 \mathrm{~cm}$ cuvette recording the consumption of $\mathrm{NADH}$. The reaction mixtures included $0.4 \mathrm{mM} \mathrm{NADH}$ (saturating concentration), together with varying concentrations of ketone

Table 1. Amino Acid Substitutions in the ADH-A Variants of Interest to the Present Work

\begin{tabular}{|c|c|c|c|c|c|c|c|c|c|c|c|}
\hline variant & 39 & 43 & 54 & 119 & $282^{* a}$ & 294 & 295 & PDB ID & resolution $(\AA)$ & cavity volume $\left(\AA^{3}\right)^{b}$ & volume difference vs wild-type $\left(\AA^{3}\right) \mathrm{L} / \mathrm{S}^{c}$ \\
\hline wild-type & $\mathrm{H}$ & $\mathrm{F}$ & $\mathrm{Y}$ & $\mathrm{L}$ & F & $\mathrm{Y}$ & $\mathrm{W}$ & $3 j \mathrm{jv} 7^{42}$ & 2.00 & $480 \pm 4$ & $(0)$ \\
\hline A1 & $o c$ & $\circ$ & $\circ$ & $\circ$ & $\circ$ & $\circ$ & A & - & - & - & - \\
\hline $\mathrm{A} 2$ & $\circ$ & $\circ$ & $\circ$ & $\circ$ & $\circ$ & $\mathrm{F}$ & A & $508 q^{38}$ & 2.21 & $730 \pm 10$ & $250 \pm 14(2 S)$ \\
\hline $\mathrm{A} 2 \mathrm{C} 3$ & $\mathrm{Y}$ & $S$ & $\circ$ & $\circ$ & $\circ$ & $\mathrm{F}$ & A & $509 f^{38}$ & 1.64 & $580 \pm 6$ & $100 \pm 10(2 S, L)$ \\
\hline $\mathrm{A} 2 \mathrm{C} 2 \mathrm{~B} 1$ & $\mathrm{Y}$ & $\mathrm{H}$ & $\mathrm{F}$ & $\circ$ & $\circ$ & $\mathrm{F}$ & A & $509 d^{38}$ & 1.79 & $610 \pm 6$ & $130 \pm 10(2 S, 2 \mathrm{~L})$ \\
\hline $\mathrm{B} 1$ & $\circ$ & $\circ$ & $\mathrm{G}$ & Y & $\circ$ & $\circ$ & 。 & $5 o d 3^{39}$ & 1.83 & $610 \pm 20$ & $130 \pm 24(2 S, L)$ \\
\hline $\mathrm{B} 1 \mathrm{~F} 4$ & $\circ$ & $\mathrm{T}$ & $\mathrm{G}$ & Y & $\mathrm{W}$ & $\circ$ & $\circ$ & $6 \mathrm{fg} 0^{39}$ & 1.74 & $630 \pm 20$ & $150 \pm 24(\mathrm{~S}, 3 \mathrm{~L})$ \\
\hline $\mathrm{C} 1$ & $\circ$ & $\mathrm{H}$ & $\circ$ & $\circ$ & $\circ$ & $\circ$ & $\circ$ & $6 \mathrm{ffx} \mathrm{x}^{40}$ & 2.49 & $590 \pm 30$ & $110 \pm 34(\mathrm{~L})$ \\
\hline $\mathrm{C} 1 \mathrm{~B} 1$ & $\circ$ & $\mathrm{H}$ & $\mathrm{L}$ & $\circ$ & $\circ$ & $\circ$ & $\circ$ & $6 \mathrm{ffz}^{40}$ & 1.71 & $690 \pm 20$ & $210 \pm 24(2 \mathrm{~L})$ \\
\hline
\end{tabular}

$a_{*}$ indicates a residue from the neighboring subunit of the dimer. ${ }^{b}$ Cavity volumes are presented as average values and standard deviations over the active site cavities of the four subunits in each asymmetric crystal cell, calculated using the CASTp server (http://sts.bioe.uic.edu/castp). "L/S" refers to either the "large" or "small" subsites of the ketone/alcohol binding sites. ${ }^{44}$ See Figure $1 \mathrm{C}$ for a schematic representation. ${ }^{d}$ The symbol ${ }^{\circ}$ indicates that the residue is the same as in the wild-type enzyme. 
(8-14). Kinetic parameters were determined after curve fitting to either the Michaelis-Menten ${ }^{46}$ or modified Hill equations ${ }^{47}$ (eq 1) using the programs MMFIT or INRATE as implemented in the SIMFIT package (www.simfit.org). F-tests were applied to warrant the use of the Hill equation, if $P \leq 0.05$.

$$
\frac{\nu_{0}}{[\mathrm{E}]_{\mathrm{tot}}}=\frac{k_{\mathrm{cat}}[\mathrm{S}]^{n}}{K_{0.5}^{n}+[\mathrm{S}]^{n}}
$$

Presteady-State Kinetics. Transient kinetics experiments were performed on an Applied Photophysics (Leatherhead, U.K.) SX20MV sequential stopped-flow spectrophotometer/ fluorometer. NADH fluorescence was excited at $340 \mathrm{~nm}$, slit width $1 \mathrm{~mm}$, and emitted light was detected after passing though a filter with a $405 \mathrm{~nm}$ cutoff. All measurements were performed at $30{ }^{\circ} \mathrm{C}$ in $0.1 \mathrm{M}$ sodium phosphate, $\mathrm{pH} 8.0,10 \mu \mathrm{M} \mathrm{ZnSO}_{4}$. Equation 2 or 4 was fitted to the recorded progression curves for determination of the apparent rates, $k_{\mathrm{obs}} . F$ is the recorded fluorescence signal, $A$, the signal amplitude, $t$, time, and $C$, the floating end point.

Coenzyme Binding. NADH binding was assayed by monitoring the increase in fluorescence occurring upon binding of the coenzyme to the active site as described previously ${ }^{38}$ but with the following modification: In the stopped flow experiment, different concentrations of $\mathrm{NADH}$ were rapidly mixed with preequilibrated mixtures of enzyme+alcohol; $0.2 \mu \mathrm{M}$ wild-type +0.4 $\mathrm{mM}(S)-4\left(12 \times K_{0.5}\right), 0.5 \mu \mathrm{M}$ A2C $2 \mathrm{~B} 1+8 \mathrm{mM}(R)-4(5.7 \times$ $\left.K_{0.5}\right), 0.5 \mu \mathrm{M} \mathrm{B} 1 \mathrm{~F} 4+3 \mathrm{mM}(S)-4\left(7.5 \times K_{0.5}\right)$, and $0.5 \mu \mathrm{M}$ $\mathrm{C} 1 \mathrm{~B} 1+8 \mathrm{mM}(S)-4\left(1.8 \times K_{0.5}\right)$.

As the progression curves displayed two distinct amplitudes with associated observed rates, the averaged progression curves $(\geq 5)$ were fitted to eq 2 , extracting two different $k_{\text {obs }}$ values.

$$
F(t)=A_{1} \exp \left(-k_{\mathrm{obs} 1} t\right)+A_{2} \exp \left(-k_{\mathrm{obs} 2} t\right)+\mathrm{C}
$$

Dissociation $\left(k_{\text {off }}\right)$ and association $\left(k_{\text {on }}\right)$ rates were determined by fitting the $\mathrm{NADH}$ concentration dependence of $k_{\mathrm{obs} 1}$ and $k_{\mathrm{obs} 2}$ to a linear (eq 3) function using program LINFIT (see Figure S2 and Table $\mathrm{S} 1$ in the Supporting Information for example progression curves, model fitting and extracted parameters).

$$
k_{\text {obs }}=k_{-5}[\mathrm{NADH}]+k_{5}
$$

Alcohol Oxidation. Pre-equilibrium mixtures of $0.2 \mu \mathrm{M}$ (wild-type) or $0.5 \mu \mathrm{M}$ (A2C2B1, B1F4, and C1B1) enzyme and $0.4 \mathrm{mM} \mathrm{NAD}^{+}$were rapidly mixed with varying concentrations of either $(S)-4$ (wild-type, B1F4, and C1B1) or (R)-4 (A2C2B1) and the presteady-state formation of $\mathrm{NADH}$ was recorded from the exponential increase in fluorescence. The apparent rates of $\mathrm{NADH}$ production, $k_{\mathrm{obs}}$, were determined from fitting a function of single exponential increase with floating end point (eq 4) to averaged progression curves $(n \geq 5)^{38}$ (Figure S3).

$$
F(t)=A \exp \left(-k_{\mathrm{obs}} t\right)+\mathrm{C}
$$

The kinetic parameters, $k_{3}$, the rate of alcohol oxidation, and $K_{2}$, where $K_{2}=k_{-2} / k_{2}$ (Scheme 1$)$ and is the dissociation constant of alcohol substrate from the ternary complex, were extracted by fitting eq 5 to the obtained rates by nonlinear regression using MMFIT (Figure S3 and Table S1).

$$
k_{\mathrm{obs}}=\frac{k_{3}[\mathrm{R}-\mathrm{OH}]}{K_{2}+[\mathrm{R}-\mathrm{OH}]}
$$

Stereoconfiguration of Alcohols Following EnzymeCatalyzed Ketone Reduction. For the analysis of the enantiomeric ratios of the alcohol products from the $\mathrm{ADH}-\mathrm{A}$ catalyzed reduction of ketones 10,11 , and $12,5 \mathrm{mM}$ of the respective ketone were mixed with $5 \mathrm{mM} \mathrm{NADH}$ in $0.1 \mathrm{M}$ sodium-phosphate, $\mathrm{pH} 8,10 \mu \mathrm{M} \mathrm{ZnSO}_{4}$, and in the presence of $20 \mu \mathrm{M}$ of either wild-type $\mathrm{ADH}-\mathrm{A}$, or the $\mathrm{A} 2 \mathrm{C} 3$ or $\mathrm{A} 2 \mathrm{C} 2 \mathrm{~B} 1$ variants. The reactions were performed at the $0.5 \mathrm{~mL}$ scale for 20 $\mathrm{h}$ at room temperature. Reaction mixtures were extracted by vortexing twice with $0.5 \mathrm{~mL}$ ethyl acetate, and the organic phases were dried under vacuum. Reaction products were dissolved in $n$-hexane:isopropanol $(80: 20, \mathrm{v} / \mathrm{v})$ and analyzed by chiral HPLC (Chiralpak AS-H, $250 \mathrm{~mm} \times 4.6 \mathrm{~mm} \varnothing$ ), using $n$ hexane/isopropanol mixtures, 95:5 (v/v) for the reactions with ketones 10 and 12 and 99:1 (v/v) for the reactions with 11, as the mobile phases. The system used an LC 20AD solvent delivery module (Shimadzu, Tokyo, Japan), a Shimadzu SIL$10 \mathrm{AF}$ autosampler, and a Shimadzu SPDM20A photometric unit with a $0.8 \mathrm{~mL} / \mathrm{min}$ flow rate. Enantiomeric ratios were calculated from the respective peak areas (Figure S4).

Molecular Dynamics Simulations of Substrate Binding to Wild-Type ADH-A and the A2 Variant. Molecular dynamics (MD) simulations were performed of wild-type ADH-A (PDB ID: $3 j v 7^{42}$ ) and the A2 variant (PDB ID: $\left.508 \mathrm{q}^{38}\right)$ in complex with alcohols $(R)$ - and $(S)-4$. The substrates were placed manually in the active site in such a fashion as to allow coordination of the hydroxyl moiety with the metal in two different starting conformations, Mode I and Mode II, where Mode $I$ is expected to be a catalytically productive starting conformation for the $(R)$-enantiomer, and Mode II is expected to be a catalytically productive starting conformation for the $(S)$ enantiomer (Figure 2, based on mutual orientation of the $\alpha$ hydride of the substrate and the cofactor). This yielded eight

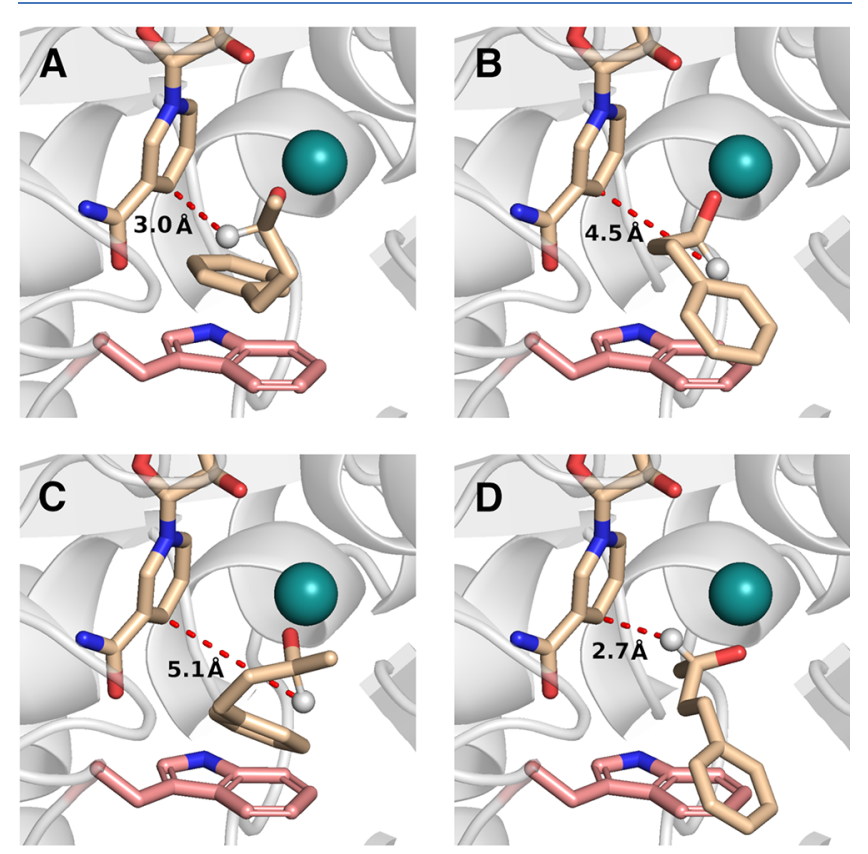

Figure 2. Initial structures used for MD simulations of wild-type ADHA, showing compound (R)-4 bound in (A) Mode I and (B) Mode II, and compound (S)-4 bound in (C) Mode I and (D) Mode II. Hydrogen-acceptor distances between the $\alpha$-hydride of the substrate and the cofactor are highlighted for each starting substrate conformation. Tryptophan 295, which restricts substrate access to the active site and is substituted in some of the variants, is shown in pink. Note that although we used a multisite model to describe the catalytic $\mathrm{Zn}^{2+}$ ion, as in our previous work, ${ }^{39}$ it is shown here using a van der Waals sphere for clarity. 
independent starting points for our MD simulations; that is, we performed simulations of each of the wild-type and $\mathrm{A} 2$ variants of $\mathrm{ADH}-\mathrm{A}$, in complex with two different enantiomers of compound 4 (Scheme 2), in each of two different binding

Scheme 2. Model of the Kinetic Mechanism of ADH-A

$\mathrm{E} \underset{k_{-1}}{\stackrel{k_{1}\left[\mathrm{NAD}^{+}\right]}{\rightleftharpoons}} \mathrm{E}^{-\mathrm{NAD}^{+}} \stackrel{k_{2}[\mathrm{R}-\mathrm{OH}]}{\underset{k_{-2}}{\rightleftharpoons}} \mathrm{E} \cdot \mathrm{NAD} \cdot \mathbf{R}-\mathrm{OH} \underset{k_{-3}}{\stackrel{k_{3}}{\rightleftharpoons}} \mathrm{E} \cdot \mathrm{NADH} \cdot \mathrm{R}=\mathrm{O} \underset{k_{-4}[\mathrm{R}=\mathrm{O}]}{\stackrel{k_{4}}{\rightleftharpoons}} \mathrm{E} \cdot \mathrm{NADH} \underset{k_{-5}[\mathrm{NADH}]}{\stackrel{k_{5}}{\rightleftharpoons}} \mathrm{E}$

modes. In the case of the wild-type enzymes, chains B and C of the tetramer in the crystal structure were used to simulate dimeric $\mathrm{ADH}-\mathrm{A}$, and in the case of the $\mathrm{A} 2$ variant, chains $\mathrm{A}$ and $\mathrm{E}$ of the crystal structure were used to simulate the dimer. For side chains with multiple occupancies, the side chain rotamer with the highest occupancy was retained for simulations. Where two side chain rotamers had equal occupancies, the first of the two possibilities were retained for the simulations. The hydrogen atoms of all titratable residues were added to the system based on predictions performed with PROPKA $3.1,{ }^{48}$ which predicted all titratable residues to be in their standard protonation states at physiological $\mathrm{pH}$. Protonation states of histidine side chains were in turn assigned on the basis of visual inspection of the local environment of each side chain, in order to maintain optimal hydrogen bonding networks.
A

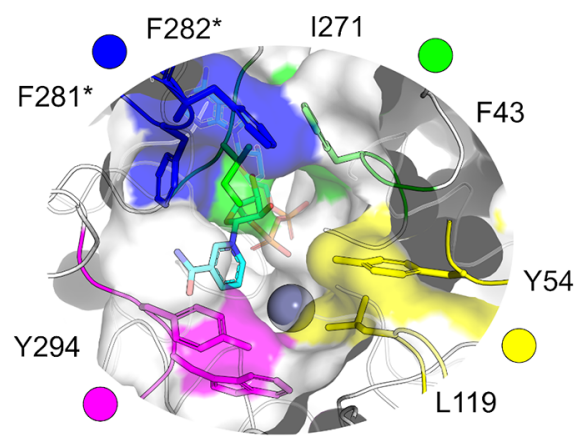

B

W295

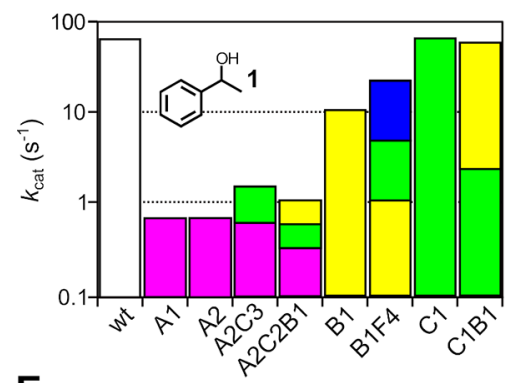

E

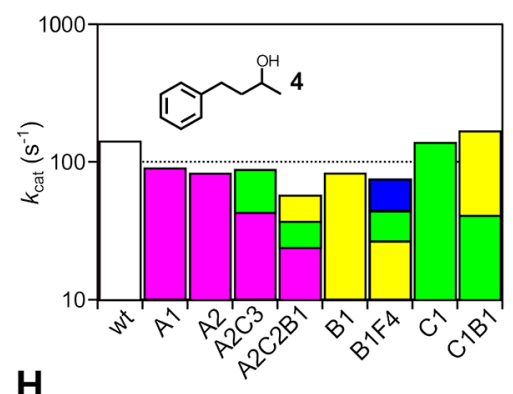

H

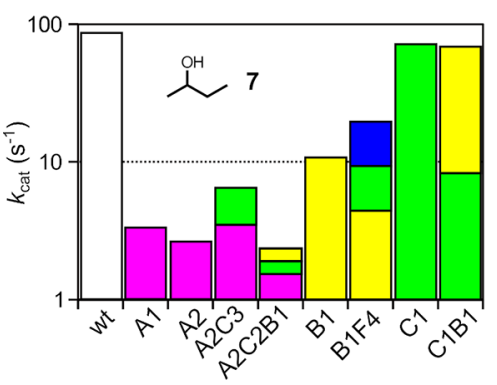

C

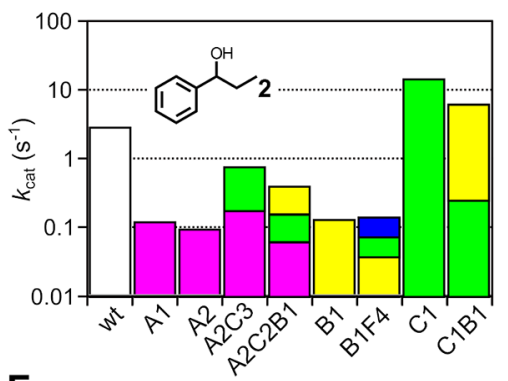

$\mathbf{F}$

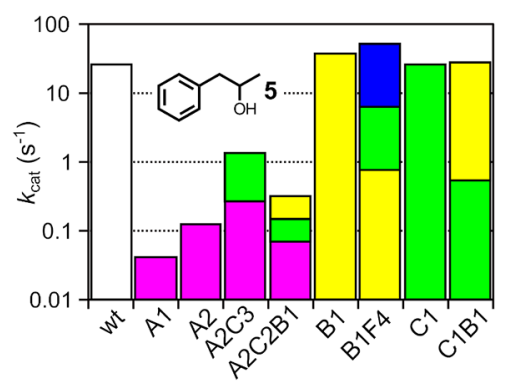

A1: W295A

A2: Y294F, W295A

A2C3: H39Y, F43S, Y294F, W295A

A2C2B1: H39Y, F43H, Y54F, Y294F, W295A

B1: Y54G, L119Y

B1F4: F43T, Y54G, L119Y, F282W

C1: $\mathrm{F} 43 \mathrm{H}$

C1B1: F43H, Y54L

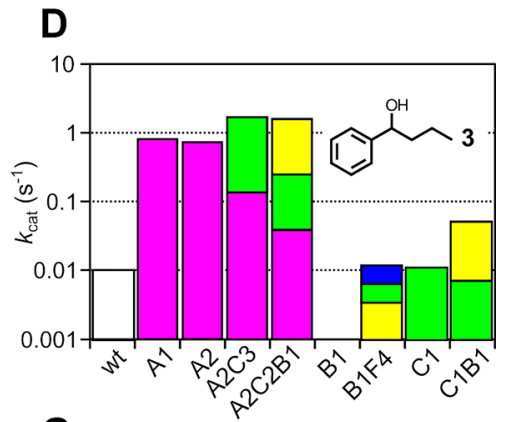

G

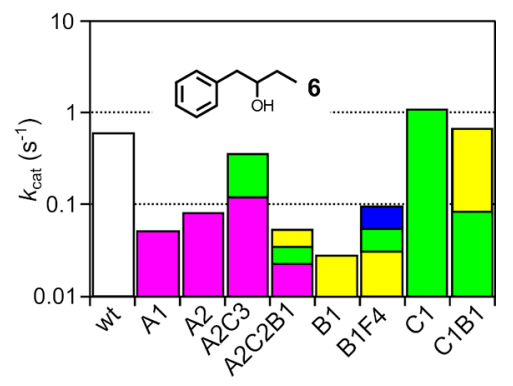

Figure 3. (A) Positions in the active site of inserted mutations color coded by mutated subsite. (B-H) Catalytic turnover numbers of wild-type (wt) $\mathrm{ADH}-\mathrm{A}$ and different enzyme variants, toward the various racemic alcohols studied in this work. The color coding of the bars indicates the contributions of mutations to the different enzyme active sites, as illustrated in panel (A). The complete data sets are shown in Table S3. 
A

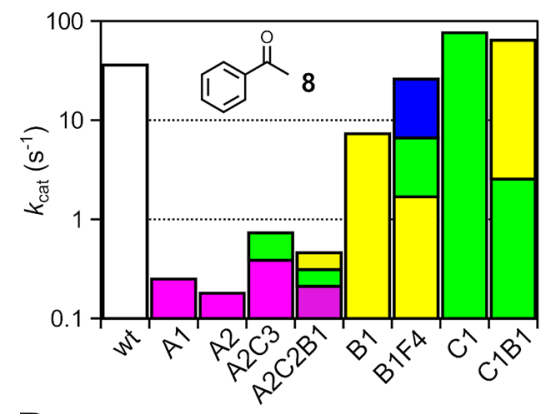

D

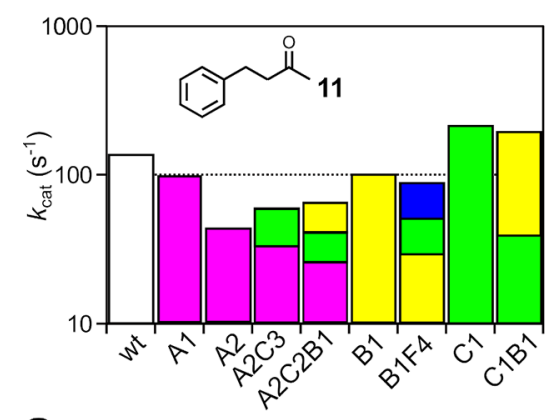

G

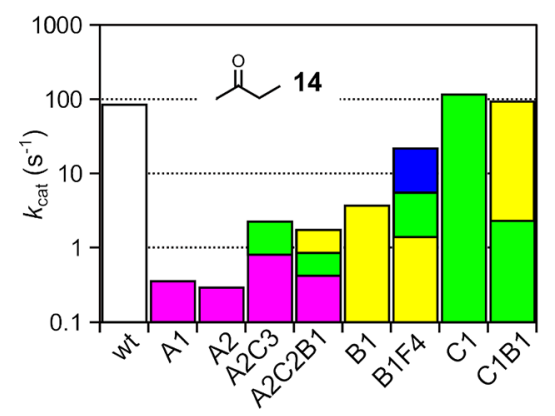

B

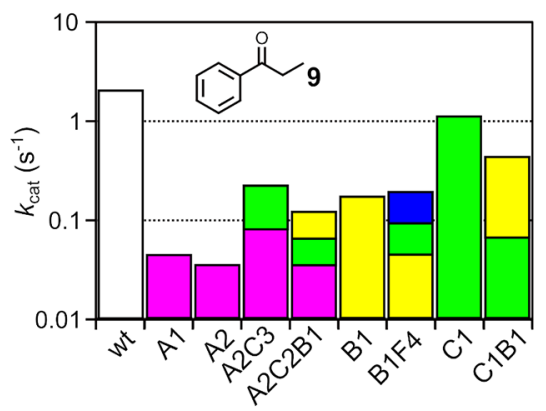

E

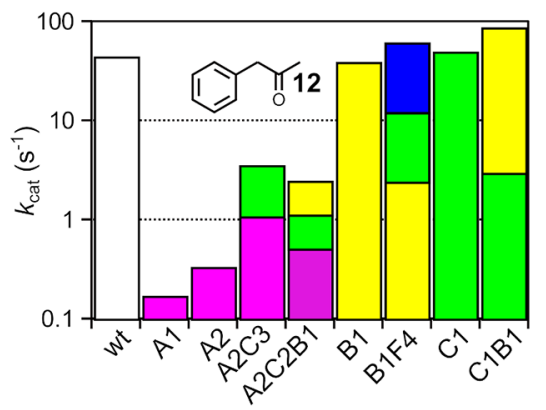

C

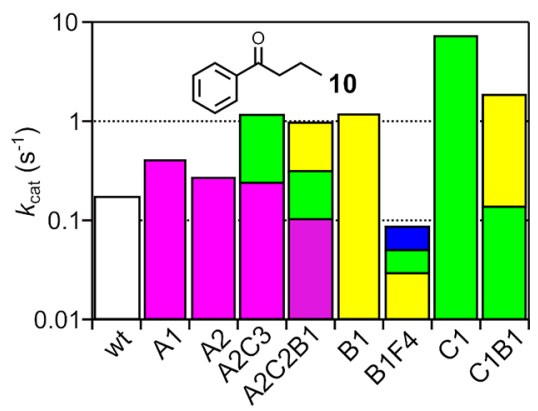

$\mathbf{F}$

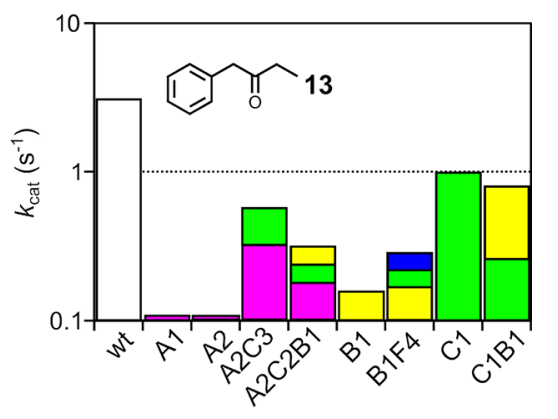

Figure 4. (A-G) Catalytic turnover numbers of wild-type (wt) ADH-A and different ADH-A variants toward the ketones tested in this work. The color coding of the bars indicates the contributions of mutations to the different enzyme active sites, as illustrated in panel Figure 3A. The complete data sets are shown in Table S4.

All simulations in this work were performed using the AMBER18 simulation package ${ }^{49}$ and the ff14SB force field ${ }^{50}$ to describe the protein. $(R)$ - and $(S)-4$ were parametrized using Antechamber ${ }^{51}$ and the General AMBER Force Field (GAFF). ${ }^{52}$ Partial charges were calculated at the HF/6-31G* level of theory, using Gaussian09, ${ }^{53}$ and then fitted using the standard RESP procotol ${ }^{54}$ (Table S2). The parameters for $\mathrm{NAD}^{+}$were taken from the literature. ${ }^{55,56}$ We then used a tetrahedral cationic dummy model to describe the two divalent zinc ions per subunit on the basis of previous successful results using this model. ${ }^{39}$ In order to prevent the nearby side chain of E63 from artificially coordinating with the metal ion, thus displacing the metal-coordinating H62 side chain, the charges of the H62 side chain were modified on the basis of examining the charge distributions obtained from quantum mechanical calculations of 4-methylimidizaole tetrahedrally coordinated to a zinc metal center, with the coordination shell completed by three extra water molecules. The atomic charges were obtained using Gaussian09 and the M11L density functional ${ }^{57}$ and the 6$31 \mathrm{G}^{*}$ basis set, with implicit solvation described using the polarized continuum model (PCM). ${ }^{58}$
All starting structures were solvated in a truncated octahedron of TIP3P ${ }^{59}$ water molecules, extending to at least $10 \AA$ from the closest solute atom. Sodium and chloride ions were added to the system to yield a $0.15 \mathrm{M}$ ion concentration using a Coulombic potential on a grid. All MD simulations were performed following the same protocol as in our previous work. ${ }^{39}$ Specifically, the systems were initially minimized in three steps while decreasing the restraints on the protein from $25 \mathrm{kcal} \mathrm{mol}^{-1}$ $\AA^{-2}$ to $0 \mathrm{kcal} \mathrm{mol}^{-1} \AA^{-2}$, and with 5000 minimization cycles, composed of 1000 steps steepest descent minimization followed by conjugate gradient minimization, at each step. The systems were then subsequently gradually heated from 100 to $300 \mathrm{~K}$ over 40 ps in an NVT ensemble, while applying weak $\left(5 \mathrm{kcal} \mathrm{mol}^{-1}\right.$ $\AA^{-2}$ ) harmonic restraints on all solute atoms. Subsequently, all systems were equilibrated for 150 ps under NPT conditions to ensure proper equilibration of the density of the system. In both equilibration steps, $20 \mathrm{kcal} \mathrm{mol}^{-1} \AA^{-2}$ harmonic distance restraints were applied to the metal-ligand geometries, with an equilibrium distance of $1.8 \AA$, in order to keep the metal geometries restrained to those observed in the crystallographic coordinates. In addition, $15 \mathrm{kcal} \mathrm{mol}^{-1} \mathrm{deg}^{-1}$ were applied to the metal-ligand angles in order to ensure tetrahedral coordination 
A

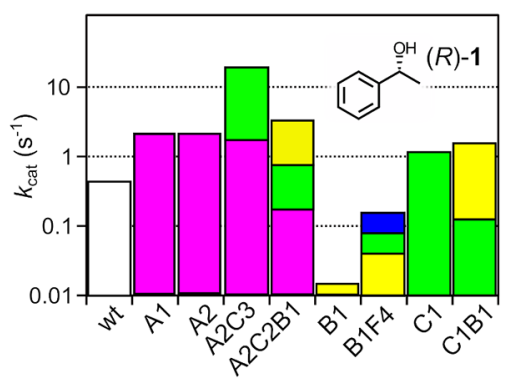

D

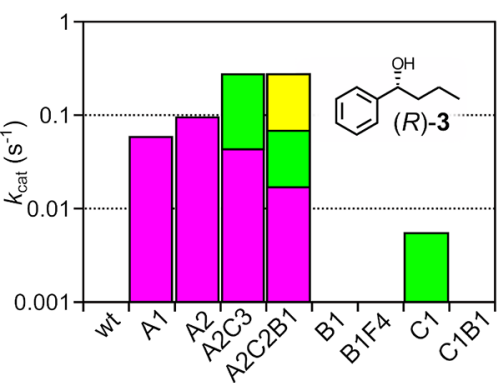

G

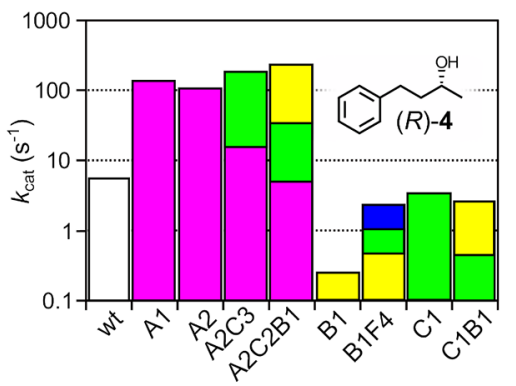

J

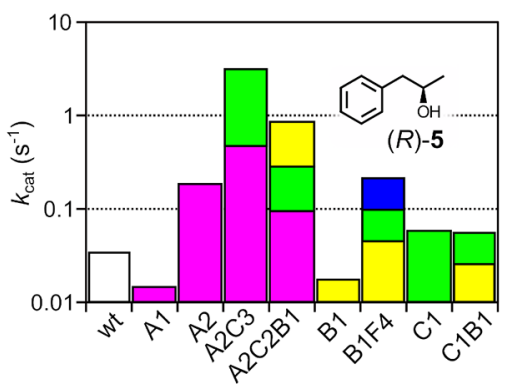

B

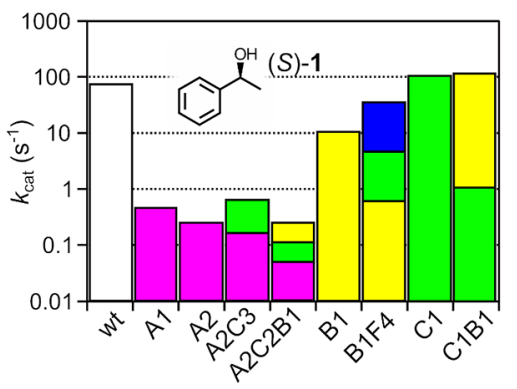

E

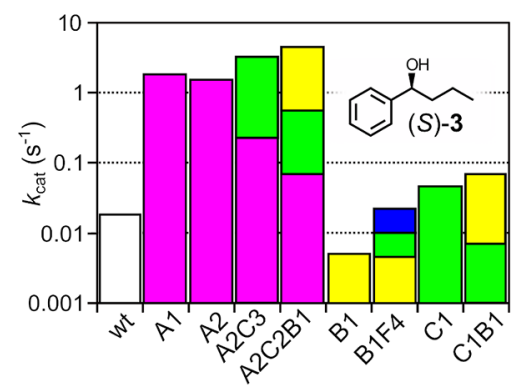

$\mathrm{H}$

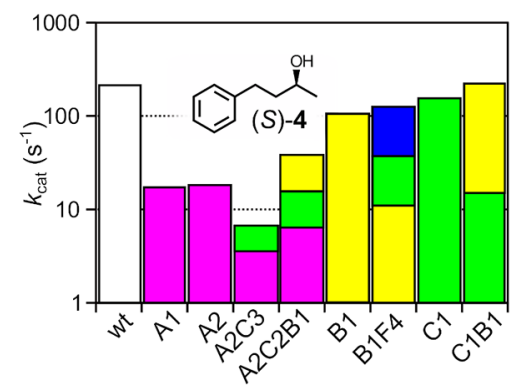

K

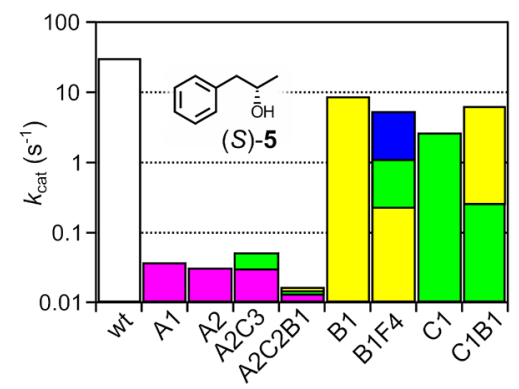

C

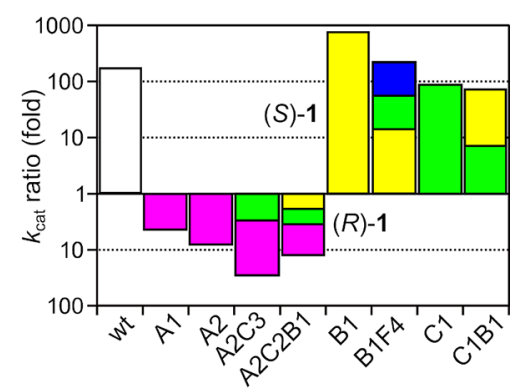

$\mathbf{F}$

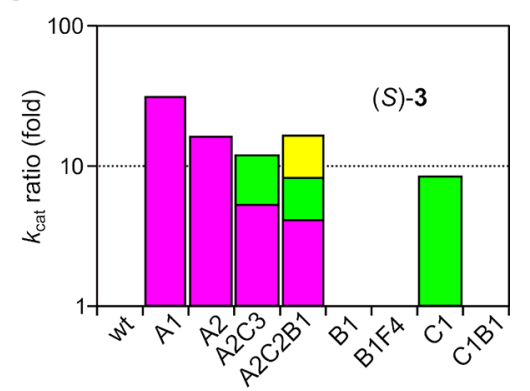

I

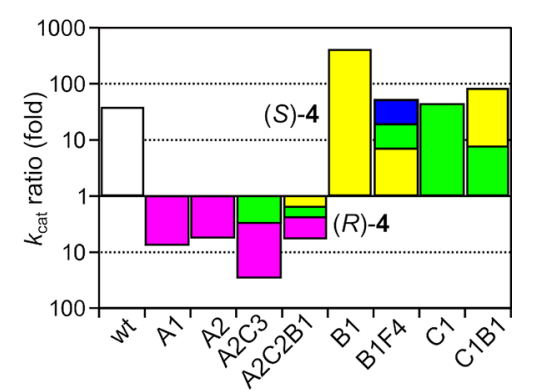

$\mathbf{L}$

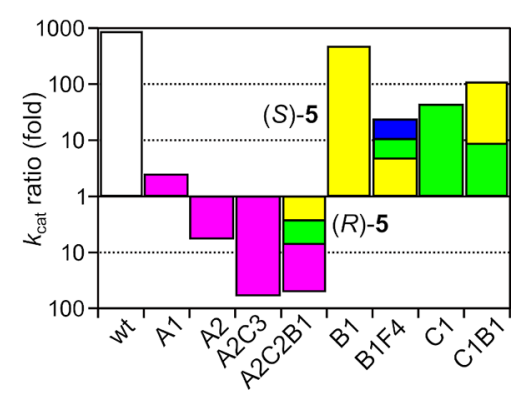

Figure 5. Catalytic turnover numbers of wild-type (wt) ADH-A and different variants toward different enantiomers of selected alcohols. Shown here in panels $(\mathrm{A}, \mathrm{D}, \mathrm{G}$, and $\mathrm{J})$ are data for activities toward the $(R)$-enantiomers of 1, 3, 4, and 5, respectively. Panels (B, E, H, and K) show the activities toward the corresponding $(S)$-enantiomers, and panels $\left(\mathrm{C}, \mathrm{F}, \mathrm{I}\right.$, and L) show the ratios of the $k_{\text {cat }}$ values of these enzymes toward the different enantiomers. The color coding of the bars indicates the contributions of mutations to the different enzyme active sites, as illustrated in Figure $3 \mathrm{~A}$. The complete data sets are shown in Table S5.

of the metal ions. These were reduced during five additional simulations of $10 \mathrm{ps}$ in length each, reducing distance restraints in $1 \mathrm{kcal} \mathrm{mol}^{-1} \AA^{-2}$ increments and angle restraints in $2 \mathrm{kcal}$ $\mathrm{mol}^{-1} \mathrm{deg}^{-1}$ increments per simulation step, with a last additional unrestrained simulation step. Additional $50 \mathrm{kcal}$ $\mathrm{mol}^{-1} \AA^{-2}$ distance restraints spanning 4.8 and $5.1 \AA$ were applied to the system during all equilibration steps in order to prevent artificial coordination of the E63 side chain to the catalytic metal ion. These restraints where switched on and off in further equilibration steps of $5 \mathrm{~ns}$ each, along $40 \mathrm{~ns}$ in an NPT ensemble to achieve stable metal coordination.
Finally, all systems were subjected to $100 \mathrm{~ns}$ of fully unrestrained production simulations (Figure S5), performed in NPT ensembles at $300 \mathrm{~K}$. A 2 fs time step was used throughout this work for all simulations, and all bonds involving hydrogen atoms were constrained using the SHAKE algorithm. ${ }^{60}$ The temperature was controlled using Langevin dynamics ${ }^{61}$ with a $1 \mathrm{ps}^{-1}$ collision frequency, and the Berendsen barostat ${ }^{62}$ was used for pressure control in the NPT ensembles. This protocol was repeated five times for each system using different initial velocities obtained by using different initial random seeds, to generate five independent MD trajectories per 
Table 2. Observed Stereoselectivities of ADH-A Catalyzed Alcohol Oxidation and Ketone Reduction

\begin{tabular}{|c|c|c|c|c|c|c|c|c|}
\hline \multirow[b]{3}{*}{ enzyme } & \multicolumn{4}{|c|}{$\mathrm{E}(\text { fold })^{a}$} & \multicolumn{4}{|c|}{ product enantiomer ratio, $(R):(S)^{b}$} \\
\hline & \multicolumn{8}{|c|}{ substrate } \\
\hline & 1 & 3 & 4 & 5 & 8 & 10 & 11 & 12 \\
\hline wild-type & $270(S)^{c}$ & $>670(S)$ & $9400(S)$ & $18000(S)$ & $<1:>99^{d}, 1$ & $<1:>99,3$ & $<1:>99,4$ & $<1:>99,5$ \\
\hline A2C3 & $1.1(S)^{d}$ & $50(S)$ & $2.2(R)$ & $4.5(R)$ & - & $49: 51,3$ & $\sim 50: 50,4$ & $46: 54,5$ \\
\hline $\mathrm{A} 2 \mathrm{C} 2 \mathrm{~B} 1$ & $7.4(R)^{d}$ & $30(S)$ & $2.6(S)$ & $4.5(R)$ & $46: 54^{d}, 1$ & $48: 52,3$ & $\sim 50: 50,4$ & $44: 56,5$ \\
\hline
\end{tabular}

${ }^{a}$ Ratio of $\left(k_{\text {cat }} / K_{0.5}\right)^{\text {major }} /\left(k_{\text {cat }} / K_{0.5}\right)^{\text {minor }}{ }^{b}$ Determined from the peak area after chiral HPLC separation. ${ }^{c}$ From ref $37 .{ }^{d}$ From ref 38 . See Figure S4 for chromatograms.

system, resulting in a cumulative 500 ns of simulation time per system, and $4 \mu \mathrm{s}$ total simulation time over all eight systems simulated in this work.

\section{RESULTS AND DISCUSSION}

In the present work, we have isolated a number of $\mathrm{ADH}-\mathrm{A}$ variants that were previously selected from CASTing libraries ${ }^{41}$

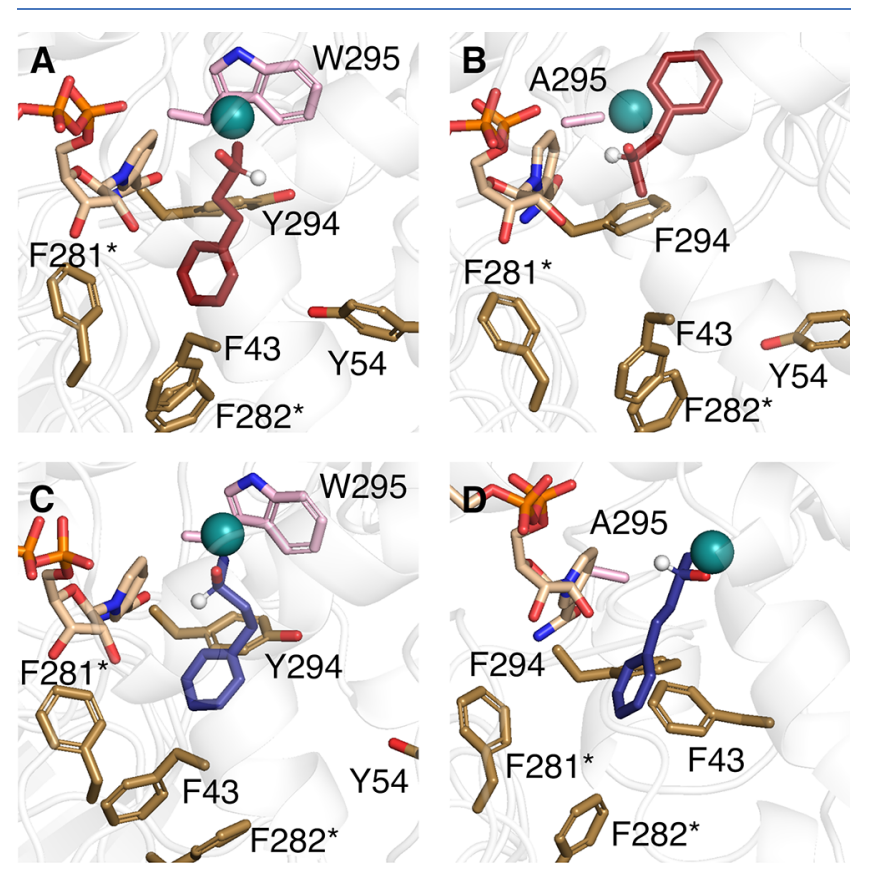

Figure 6. Representative structures of Michaelis complexes of initially productive Mode I for (R)-4 (brown) in complex with (A) wild-type $\mathrm{ADH}-\mathrm{A}$ and (B) A2 variant, as well as the initially productive Mode II for (S)-4 (dark purple) in complex with (C) wild-type ADH-A and (D) A2 variant. Key mutation W295/A295 in A2 variant is shown in pink. Note that although we used a multisite model to describe the catalytic $\mathrm{Zn}^{2+}$ ion, as in our previous work, ${ }^{39}$ it is shown here using a van der Waals sphere for clarity. This data was obtained by RMSD-based clustering using a hierarchical algorithm over five independent $100 \mathrm{~ns}$ $\mathrm{MD}$ simulations performed on each system, as described in the Materials and Methods.

for different purposes and functions (Table 1). These novel enzyme variants serve both as model systems in our efforts to decipher evolutionary pathways to new catalytic functions, as well as potentially new and valuable biocatalysts.

In order to map the catalytic turnover efficiencies of the different enzyme-substrate combinations, the collection of alcohols studies in this work (Scheme 1) were initially tested as racemic mixtures. Subsequently, the activities of wild-type $\mathrm{ADHA}$ and its variants toward pure enantiomers of four selected alcohols $(1,3,4$, and 5) were further analyzed in order to assess the enantioselectivities of the oxidative reactions. Since $k_{\text {cat }}$ is directly linked to rate-limiting reaction steps of catalysis, this parameter was of primary interest rather than values of $k_{\mathrm{cat}} / K_{\mathrm{M}}$. Furthermore, the potential usefulness of these enzymes as biocatalysts would benefit more from high values of $k_{\text {cat }}$, which reflects the reaction velocity at the high substrate load (i.e., saturating conditions, eq 6) expected to be present in a synthetic reaction mixture.

$$
V_{\max }=k_{\text {cat }}[\mathrm{ES}] ;[\mathrm{ES}] \simeq[\mathrm{E}]_{\mathrm{tot}}
$$

The steady-state turnover rates of all tested enzyme-rac-alcohol/ ketone combinations are shown in Figures 3 and 4 with the numerical values of the different parameters listed in Tables S3 and S4 in the Supporting Information.

$\mathrm{ADH}-\mathrm{A}$ catalyzed reactions follows an ordered sequential $\mathrm{BiBi}$ mechanism with binding and release of the cofactor(s) as the initial and final steps (Scheme 2), although an iso-TheorellChance mechanism can not be excluded. ${ }^{37,38}$ The dissociation rates of $\mathrm{NADH}$ or $\mathrm{NAD}^{+37}$ and the relatively small primary deuterium kinetic isotope effect on $k_{\text {cat, }}{ }^{38}$ strongly suggest that nucleotide release is rate limiting in the wild-type catalyzed oxidation of the favored substrate $(1 S)$-phenylethanol $((S)-\mathbf{1}$, Scheme 1) and in the reduction of the corresponding ketone acetophenone (8). However, with many substrates, the values of $k_{\text {cat }}$ are considerably lower than the slowest microscopic rates, which suggest that nonproductive substrate binding also influences turnover, as well as affecting stereo- and regioselectivities. ${ }^{37-40}$

It should be noted that measuring the steady-state kinetics with many of the tested enzyme-substrate combinations is not trivial, and the substrate concentration dependency of initial rates cannot be accurately modeled by the first-order MichaelisMenten equation under the pseudo-first-order conditions applied here. A first complication is the different degrees and types of cooperativity that these enzymes exhibit; a given substrate may elicit either positive, negative, or no cooperativity depending on the enzyme variant. As an example, the wild-type ADH-A catalyzed oxidation of 1-phenyl-1-propanol (2), shows strong negative cooperativity, with a Hill coefficient $<1 \quad(n=$ $0.29)$, as do variants $\mathrm{B} 1, \mathrm{~B} 1 \mathrm{~F} 4$ and $\mathrm{C} 1(n=0.26-0.61)$. However, the remaining enzyme variants display "normal" Michaelis-Menten saturation kinetics $(n=1)$ with the same substrate (Table S3, Figure S6A). The reduction of the corresponding ketone, propiophenone (9) also induces strong negative cooperativity $(n=0.55-0.74)$ in wild-type $\mathrm{ADH}-\mathrm{A}$, as well as in the A1 and A2 variants. Further substitutions on the A2 background in the $\mathrm{A} 2 \mathrm{C} 3$ and $\mathrm{A} 2 \mathrm{C} 2 \mathrm{~B} 1$ variants shifts the behavior of the enzyme toward slightly positive cooperativity ( $n$ $=1.1$ in the $\mathrm{A} 2 \mathrm{C} 2 \mathrm{~B} 1$ variant). This is accentuated in the $\mathrm{B} 1$ and B1F4 variants $(n=1.2)$, while $\mathrm{C} 1$ and $\mathrm{C} 1 \mathrm{~B} 1$ do not exhibit cooperative behavior with this substrate (Table S4, Figure S6B). Thus, the $\mathrm{B} 1$ and $\mathrm{B} 1 \mathrm{~F} 4$ variants switch from negative to positive 

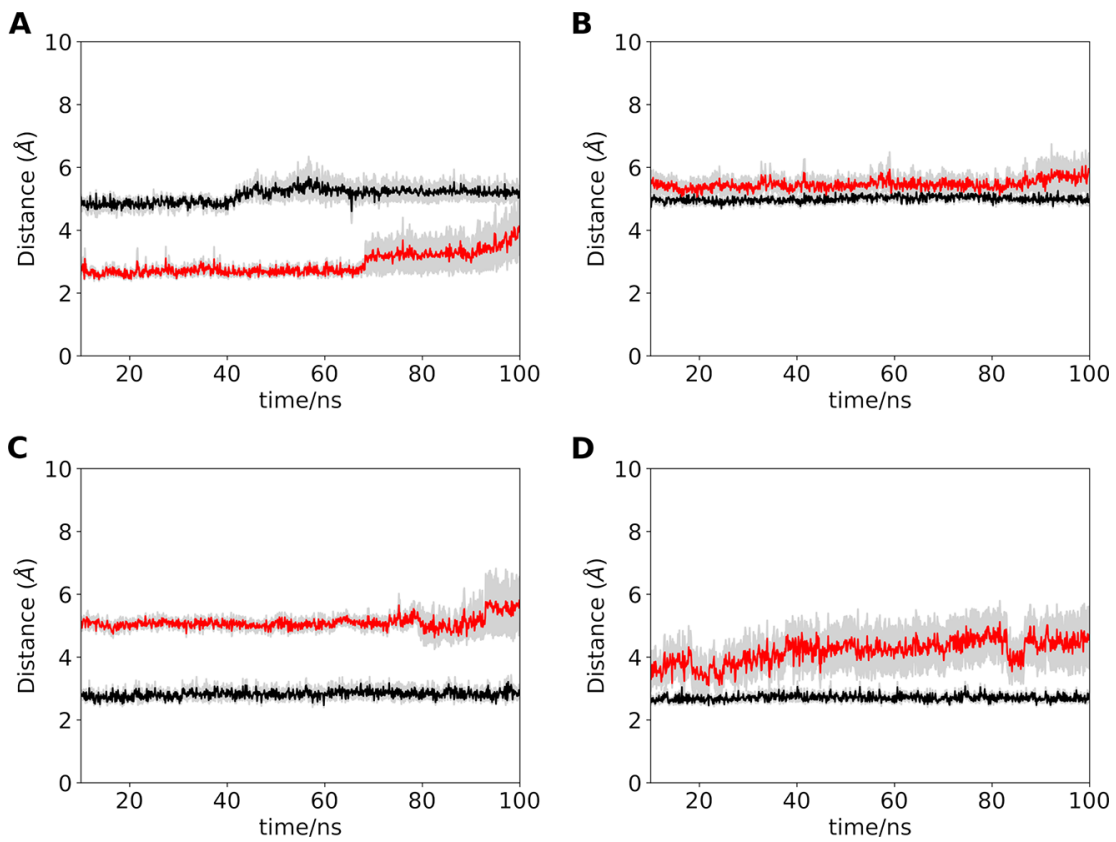

Figure 7. Time evolution of the distances between the $\alpha$-hydride of compounds $(R)-4$ and $(S)-4$, and the C-4 atom of the nicotinamide group of $\mathrm{NAD}^{+}$, during molecular dynamics simulations of Michaelis complexes of wild-type $\mathrm{ADH}-\mathrm{A}$ (black) and the $\mathrm{A} 2$ variant (red), in complex with (A) ( $R$ )4 bound in Mode I, (B) (R)-4 bound in Mode II, (C) $(S)-\mathbf{4}$ bound in Mode I and (D) (S)-4 bound in Mode II. The solid lines denote averages, and the shaded lines denote standard of the mean over five independent MD trajectories propagated for each system. Data was collected every 100 ps. For representative structures from each simulation, see Figures 6 and S7, and for the corresponding average values and standard deviations for each simulation, see Table S6.

cooperative behavior upon moving from alcohol oxidation to ketone reduction. As the geometric constraints in the reduction and oxidation reactions, as well as the polarity of the respective substrates are expected to be different, it is not surprising, per se, that the kinetic behavior concerning cooperativity also differs between these systems.

The difference in sequence and structure between wild-type $\mathrm{ADH}-\mathrm{A}$ and the $\mathrm{C} 1$ variant comes down to a single $\mathrm{F} 43 \mathrm{H}$ mutation. However, although the side chain volumes of these residues are similar $\left(\Delta V \sim 20 \AA^{3}\right)$, the substitution widens the active-site cavity volume by $\sim 100 \AA^{3}$ (Table 1 ) due to a $\sim 90 \mathrm{deg}$ shift in the position of the side chain. This places the imidazole group perpendicular to the phenyl substituent of F43, allowing it to interact with the ribose cofactor via hydrogen bonding interactions to the $2^{\prime}$ and $3^{\prime}$ hydroxyls groups (Figure $\mathrm{S} 1 \mathrm{H}$ ). The observed differences in cooperativity with propiophenone can thus be traced back to this relatively small structural change. Apart from the differences in cooperative behaviors, the catalytic efficiencies, expressed as $k_{\text {cat }}$ with this substrate are comparable (Figure 4). All variants that exhibit no, or positive cooperativity, with propiophenone, which the exception of the $\mathrm{B} 1$ variant, contain amino acid substitutions at position 43 (F43H, F43S, or F43T, Table 1), which have all been demonstrated to introduce new hydrogen bonding interactions with the coenzyme ribose. $^{38,39}$ The Y54G/L119Y substitutions in the B1 variant seem to instead allow for the substrate to bind in such a way as to result in the observed moderate positive cooperativity with this substrate bound in the active site. The detailed underlying causes of the observed differences in cooperative behavior are unknown but may be speculated to result from alterations in the structural dynamics of the system as a consequence of the amino acid substitutions introduced in this variant. That is, the mutations may lead to changes in key interaction networks, for example, as caused by the $\mathrm{F} 43 \mathrm{H}$ substitution, which results in new enzyme-cofactor bonds. ADH-A is an obligatory dimer, in which both subunits contribute structural elements to the respective active sites. It is therefore conceivable that local changes in dynamic properties would affect substrate concentration-dependent kinetics differently. The different alcohol enantiomers may also elicit different degrees of cooperativity. Furthermore, substrate inhibition is commonly observed, and thus, the kinetic parameters listed here (Tables S3-S5) have been determined from the concentration dependency of the initial reaction velocities in the substrate concentration range preceding substrate inhibition.

Steady-State Reactions of Wild-Type ADH-A and Variants with Racemic Alcohols and Ketones. In general, wild-type $\mathrm{ADH}-\mathrm{A}$ displays the overall highest activities of all enzyme variants studied in this work toward the tested alcohols and ketones (Figures 4, 5) and can be described as the most promiscuous "generalist" enzyme of the selection. However, the "promiscuity" in this case is limited to acceptance of diverse substrate structures and does not imply catalytic promiscuity $^{19,63}$ or even relaxed stereoselectivity since wild-type $\mathrm{ADH}-\mathrm{A}$ strongly prefers ketone substrates that obey the Prelog rule of re face attack resulting in $(S)$ configuration of the resulting alcohol, and vice versa for alcohol oxidation. ${ }^{34,37}$

The ADH-A variants included here were all selected during the iterative mutagenesis and selection regimes for specific traits: $\mathrm{A} 1, \mathrm{~A} 2, \mathrm{~A} 2 \mathrm{C} 3$, and $\mathrm{A} 2 \mathrm{C} 2 \mathrm{~B} 1$ were isolates from different enzyme generations selected for improved activity toward the normally nonpreferred $(R)$-enantiomer of 1-phenylethanol $(\mathbf{1}) .^{38}$ The B1 and B1F4 variants were selected for activity toward the disubstituted sec-alcohol (1R,2S)-1-phenyl-1,2-propanediol, and display altered regioselectivities as compared to the wildtype enzyme. ${ }^{39}$ The $\mathrm{C} 1$ and $\mathrm{C} 1 \mathrm{~B} 1$ variants were selected for increased activity toward the vicinal diol (1R)-1-phenyl-1,2ethanediol. $^{40}$ These enzyme variants therefore comprise a 
A
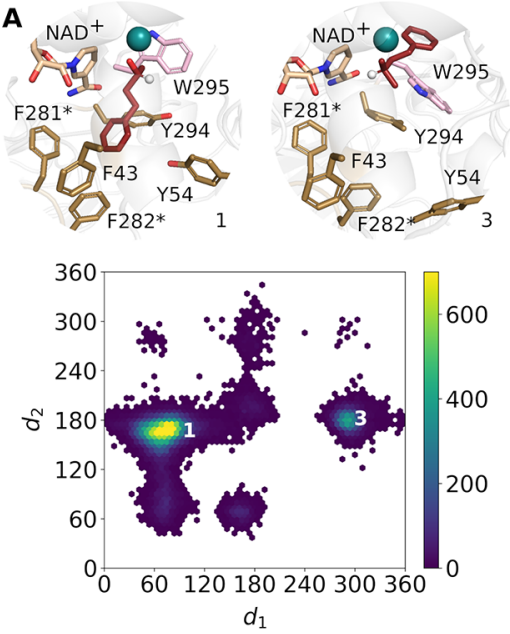

C
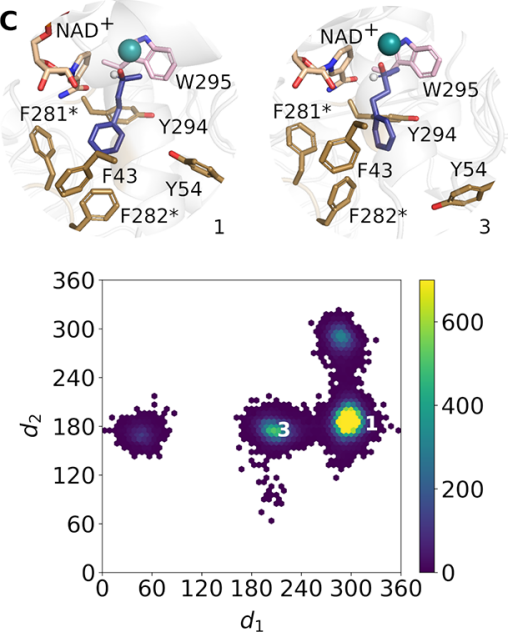
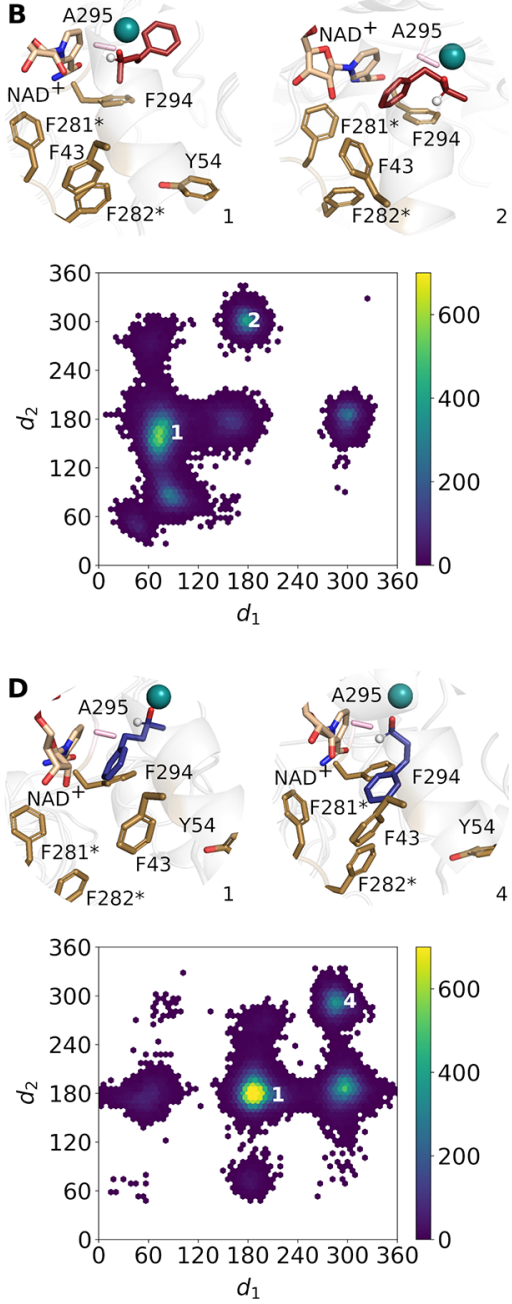

Figure 8. Joint distributions of the $d_{1}$ and $d_{2}$ dihedral angle values sampled during molecular dynamics simulations of Michaelis complexes of wild-type ADH-A and the A2 variant, in complex with (A) (R)-4 bound in Mode I, (B) (R)-4 bound in Mode II, (C) (S)-4 bound in Mode I, and (D) (S)-4 bound in Mode II, together with representative structures, selected on the basis of clustering analysis using a hierarchical clustering algorithm over five independent $100 \mathrm{~ns} \mathrm{MD}$ simulations performed on each system, of the most populated dihedral angle combinations. Cluster population and distance between the $\alpha$-hydride and C-4 atom of the cofactor on each cluster are shown in Tables S7 and S8. The $d_{1}$ dihedral angle involves the C10-C9-C8C7 atoms of the substrate, while $d_{2}$ involves C9-C8-C7-C6 atoms (* refers to residues from the neighboring subunit, see Figure S8).

spectrum of slightly varying active site structures (Figure S1) and would thus be expected to display different substrate-, regio-, and stereoselectivities, as well as when challenged with potential substrates that they were not originally targeted for. The alterations within the respective active sites are located at different regions of the active-site cavities (Figure 1B).

An exception to the broad substrate scope of the wild-type enzyme is rac-3, 1-phenyl-1-butanol, which is oxidized $\sim 100$ fold more efficiently by the W295A containing variants (A1, A2, $\mathrm{A} 2 \mathrm{C} 3$, and $\mathrm{A} 2 \mathrm{C} 2 \mathrm{~B} 1$ ) than the wild-type enzyme. The $\mathrm{C} 1$ variant $(\mathrm{F} 43 \mathrm{H})$ displays 5 -fold and $\sim 40$-fold higher $k_{\text {cat }}$ values, as compared to the wild-type, in the oxidation of 1-phenyl-1propanol (2) and in the reduction of butyrophenone (10), respectively. However, in both these reactions, the $\mathrm{C} 1$ enzyme displays strong negative cooperativity $(n=0.38-0.49)$ which obscures exact rate determinations. The variants containing the W295A substitution (A1, A2, A2C3, and A2C2B1) display the lowest turnover numbers with the tested racemic alcohols and ketones with the exception of the aforementioned $\mathrm{rac}$-3, ketone 10, and rac-4. The underlying reasons for the relatively higher turnover numbers with rac-3 and $\mathbf{1 0}$ may be due to that the loss of the indole group creates new cavity space in the active sites (Figure S1C-E) that accommodate new productive substrate binding modes of rac-3 and $\mathbf{1 0}$ but that can also lead to nonproductive binding modes with other substrates, resulting in lower overall activities. In all cases, the active site cavities become enlarged, as judged by the CASTp analysis (Table 1).

Steady-State Reactions of Wild-Type ADH-A and Variants with Enantiopure Alcohols. The enzyme activities of $\mathrm{ADH}-\mathrm{A}$ and its variants toward racemic mixtures of alcohols $\mathbf{1}, \mathbf{3}, \mathbf{4}$, and 5, were further dissected through steady-state kinetic analysis of the respective enantiomers. The determined turnover numbers are shown in Figure 5 with the complete parameter data sets shown in Table S5. Compounds 1, 4, and 5 are structurally related, in that they are all 1-methyl substituted alcohols, but with phenyl-alkyl substitutions of different lengths.

Earlier studies have explained the strong $(S)$-selectivity of ADH-A toward 1-phenyl-1-ethanol (1). ${ }^{37,38,42}$ Specifically, the model places the phenyl substituent of $(S)-1$ in contact with the indole side chain of W295, thus placing the $\alpha$-hydride of the substrate in the perfect position for transfer to $\mathrm{NAD}^{+}{ }^{38}$ In conjunction with this, the same substrate binding mode will 
become nonproductive in the case of the $(R)$-enantiomer of compound $\mathbf{1}$, as, in this case, the $\alpha$-hydride points away from the nictotinamide group of $\mathrm{NAD}^{+}$. Replacement of W295 by Ala, as in variants $\mathrm{A} 1, \mathrm{~A} 2, \mathrm{~A} 2 \mathrm{C} 3$, and $\mathrm{A} 2 \mathrm{C} 2 \mathrm{~B} 1$, allows for reorientation of the phenyl substituent leading to more productive binding modes, and increased $k_{\text {cat }}$ values toward $(R)-1 .^{38}$ In parallel, the activity with $(S)$-1 decreases drastically, supposedly due to the introduction of new, nonproductive binding modes in the enlarged active sites. Similar scenarios can be envisioned also with ( $R$ )-4, and (R)-5 tested here; the larger cavity formed by the W295A substitution can allow for binding modes that also accommodate productive binding of these substrates to larger degrees and at the same time increase the likelihood of nonproductive binding events with the corresponding $(S)$ enantiomers of these compounds. This hypothesis is supported by the ratios of the turnover numbers with the respective enantiomers (Figure 5C,I,L). That is, the W295A substituted variants display generally higher $k_{\text {cat }}$ values with all three $(R)$ enantiomers, as compared with any of the other $\mathrm{ADH}-\mathrm{A}$ variants tested here, but in all cases exhibit lower turnover numbers toward the corresponding $(S)$-enantiomers. Hence, the W295A substitution appear to be a decisive structural alteration in the switch from $(S)$ selectivity to $(R)$, with these alcohols. This is at least true in the comparisons of $k_{\text {cat }}$; when comparing $k_{\text {cat }} / K_{0.5}$, the same trend is still present but less pronounced due to compensating low values of $K_{0.5}$ (Table S5).

The importance of a Trp residue in discriminating the stereooutcome of ketone reduction has been described also in the related $\mathrm{ADH}$ from Candida parapsilosis. Mutations of the corresponding Trp residue (W286A), positioned similarly to W295 in ADH-A, shifts the stereoconfiguration of the product following reduction of substituted acetophenones from Prelog to anti-Prelog ${ }^{64}$ and a W286S substitution enables the enzyme to accept methyl- $(R)-3$-hydroxybutyrate instead of the $(S)$ enantiomer, as substrate. ${ }^{65}$

Single-residue substitutions have been demonstrated to alter stereoselectivities also in other ADHs; Biehl and co-workers changed the enantiomeric product alcohol ratios, from $(R)$ to $(S)$ in the reduction of methyl or chloro substituted benzophenones by a single Q245P mutation in an $\mathrm{ADH}$ from Sporobolomyces salmonicolor AKU4429. ${ }^{66}$ Also, an I86A substitution, enlarging the small subsite in the $\mathrm{ADH}$ from Thermoanaerobacter ethanolicus, allowed binding and reduction of acetophenone derivatives, and furthermore, shifted the stereochemical outcome of the alcohol products to anti-Prelog configuration. ${ }^{67}$ The starting point in that case was different as compared to the effects in $\mathrm{ADH}-\mathrm{A}$, in that the unmutated enzyme did not accept acetophenone or 1-phenylethanol as substrates. Reetz and co-workers further developed the stereoselectivity of the closely related T. brockii isoenzyme by applying CASTing and site-directed mutagenesis. The results again pin-pointed I86 as a crucial residue in deciding the stereochemical outcome of ketone reduction and an I86N substitution, similarly to the I86A in T. ethanolicus, which allowed the enzyme to reduce acetophenone with anti-Prelog configuration in the product. Interestingly, a W110M substitution inverted the product stereochemistry back to generate (S)-1-phenylethanol. ${ }^{68}$ W110 appear from the crystal structure of $T$. brokii $\left(1 \mathrm{ykf}^{69}\right)$ to be positioned in a position approximating that of W295 in ADH-A, restricting the positioning of a bulky substrate substituent. The roles of residues I86 and W110 in stereodiscrimination of the $T$. brockii $\mathrm{ADH}$ has more recently been further investigated and rationalized by MD simulations. ${ }^{70}$
Racemic 1-phenyl-1-butanol (3) is a relatively better substrate for the variants containing the W295A substitution, as compared with the other enzymes tested here (Figure 3 ). However, in this case, the $(S)$-3 isomer is favored over the $(R)$-enantiomer (Figure $5 \mathrm{~F}$ ). It is noteworthy that $(R)-3$ is not transformed to any detectable degree by either of the wild-type, the B1, B1F4, or C1B1 variants. Hence, The W295A mutation has unveiled a hidden activity in the $\mathrm{A} 1$ variant and its relatives.

$(S)$-4-Phenyl-2-butanol (S-4) and the cognate ketone $\mathbf{1 1}$ are transformed with notably high catalytic efficiencies by wild-type $\mathrm{ADH}-\mathrm{A}$ and the $\mathrm{C} 1$ and $\mathrm{C} 1 \mathrm{~B} 1$ variants. The $k_{\text {cat }}$ values displayed by these enzymes are considerably faster than the previously estimated dissociation rates of the respective $\mathrm{NADH}$ and $\mathrm{NAD}^{+}$ cofactors (Table S1) and thus challenge the proposed kinetic model of a strictly ordered $\mathrm{BiBi}$ mechanism. The same situation is observed also for the combination of $(R)-4$ and the A2C2B1 variant, with a $k_{\text {cat }}=240 \mathrm{~s}^{-1}$, which is 4 -fold higher than the previously reported value of the NADH off-rate, $k_{5}=65 \mathrm{~s}^{-138}$ (Tables S1 and S5). It should be noted that the nucleotide dissociation rates determined previously ${ }^{38-40}$ and used here for comparisons were recorded in standard stopped flow measurements, in which the free enzyme and cofactor were mixed after which the binding/dissociation process was followed in real time. Thus, the rates of cofactor release were determined in the absence of a second substrate, in accordance with an ordered kinetic model (Scheme 1). Even though we have not been able to confirm the presence of an additional conformational transition of the enzyme-cofactor(s) binary complex(es) as have been described for the horse liver isoenzyme, ${ }^{71}$ it can not be excluded that the kinetic dissociation rates of the cofactors are different during the steady-state reaction phases. It can also not be absolutely excluded that the $\mathrm{ADH}-\mathrm{A}$ variants analyzed here exhibit an increased degree of randomness in the order of substrate binding, and this possibility was not tested. However, in these $\mathrm{NADH}$ association/dissociation rate determinations, the wild-type enzyme was the subject in three out four study cases (with the A2C2 variant complementing together with $(R)$ 4, and the wild-type does follow an ordered mechanism.

Pre-Steady State Kinetics. In an attempt to more closely resemble the situation in the ternary $\mathrm{E} \cdot \mathrm{R}=\mathrm{O} \cdot \mathrm{NADH}$ complex, the NADH binding/dissociation was studied after mixing it with a pre-equilibrated mixture of enzyme and alcohol. The rational being to investigate if structural and/or dynamic properties of the enzyme-NADH interactions are influenced by the presence of a second substrate/product in the active site. The results clearly suggest that such interdependency exists; first, the presteady-state binding and dissociation, recorded as exponential increases in $\mathrm{NADH}$ fluorescence, required a second order exponential function (eq 2), to accurately model the binding/ dissociation of NADH to the enzyme-alcohol complexes. This behavior has not been observed previously in similar studies mixing free enzyme and coenzyme only. Second, fitting the fastest of the apparent observed rates $\left(k_{\mathrm{obs} 1}\right)$ to a linear dependency of the $\mathrm{NADH}$ concentration to obtain the microscopic association and dissociation rates, $k_{-5}$ and $k_{5}$, respectively, results in $\mathrm{NADH}$ off-rates that are significantly faster than $k_{\text {cat }}\left(k_{5}{ }^{\prime}\right.$ and $k_{5}{ }^{\prime \prime}$ in Table $\left.S 1\right)$. These data now agree well with a sequential ordered mechanism. The electrostatics and local dynamics of the active site microenvironment, together with substrate-induced cooperativity, may affect the $\mathrm{NADH}$ affinity to become different from those in isolated enzymecofactor binary systems. It is noteworthy, however, that in the case of $\mathrm{C} 1 \mathrm{~B} 1 \cdot(S)-4 \cdot \mathrm{NADH}$, the estimated value of the $\mathrm{NADH}$ 
dissociation rate is slower than the corresponding $k_{\text {cat }}{ }^{(S)-4},(140$ $\mathrm{s}^{-1}$ as compared with $230 \mathrm{~s}^{-1}$ ) albeit faster than previously determined in the binary C1B1·NADH setup $\left(93 \mathrm{~s}^{-140}\right)$. This is, however, a somewhat special case because it is the only combination of enzyme and substrate where alcohol saturation of the enzyme was not possible to achieve because of the combination of a high half-saturation concentration $\left(K_{0.5}\right)$ and relatively low solubility of the alcohol. The possibility that the particular properties of the enzyme-cofactor-product ternary complex may influence catalytic turnover has been proposed earlier for the equine isoenzyme, in the context of increasing the rate of a rate-limiting conformational change of the enzyme$\mathrm{NADH}-$ aldehyde complex. ${ }^{72}$ Hence, the putative effect on substrate/product dependent increase in the $\mathrm{NADH}$ off-rate may not be fully expressed in this substrate-enzyme combination. The oxidation rates of either enantiomer of 4 are clearly not rate limiting, exceeding $k_{\text {cat }}$ values by 2.4- to 5.4-fold (Table S1). Linear fitting of the $[\mathrm{NADH}]$ dependency of $k_{\text {obs2 }}$ yields respective rates that are too slow to be on the productive pathway (Figure S2), and their origins are currently unknown.

Stereoselectivity. The enantioselectivities of alcohol oxidation by different $\mathrm{ADH}-\mathrm{A}$ variants were determined from the ratios of the respective $k_{\text {cat }} / K_{0.5}$ values (Tables 2 and S5). The results are largely in line with the ratios of turnover numbers (Figure 5), with the W295A containing variants displaying $(R)$ preference in the cases of alcohols 1, 4, and 5. The stereochemical outcomes in the reverse reactions, that is, the reduction of the cognate ketones are not necessarily mirroring the enantiopreferences in the alcohol oxidations. Reduction of acetophenone (8) catalyzed by wild-type $\mathrm{ADH}-\mathrm{A}$ results exclusively in $(S)-\mathbf{1}$, in line with the enantioselectivity in the oxidations of $(R)$-, and $(S)-\mathbf{1}$. However, even though the $\mathrm{A} 2 \mathrm{C} 2 \mathrm{~B} 1$ variant displays a preference for $(R)-\mathbf{1}$, the enymecatalyzed reduction of 8 results in a racemic mixture of the alcohol products. ${ }^{38}$ The same behavior is observed here; the alcohol products of the A2C3- or A2C2B1-catalyzed reduction of 10,11 , or 12 , all result in essentially racemic mixtures of the enantiomers, with a possible modest preference for production of the $S$ enantiomers (Table 2). The chromatographic resolution of the enantiomers of 4 was poor (Figure S6), which prevented accurate determinations of the $(R) /(S)$ ratios. Thus, the enlarged active sites in these variants allow for (i), productive binding of (R)-4, and (R)-5, and both enantiomers of 3, (ii) these active-site cavities also accommodate hydride addition to either the si or re faces of the corresponding ketones, thereby resulting in racemic alcohol mixtures. Hence, for biocatalytic production of enantiopure alcohols, the wild-type enzyme provide the possibilities for production of enantiopure $(S)$ enantiomers of $1,3,4$, and 5 following reduction of the corresponding ketones, whereas the corresponding $R$-enantiomers may be achieved by kinetic resolution during oxidation of the racemic alcohol mixtures.

Molecular Dynamics Simulations. In addition to our biochemical characterization, we also performed MD simulations of wild-type $\mathrm{ADH}-\mathrm{A}$ and the $\mathrm{A} 2$ variant, in complex with both $(R)$ - and $(S)$-enantiomers of compound 4 , as described in the Materials and Methods. The goal of these simulations is to further explore the role of the W295A substitution in the switch from $(S)$ - to $(R)$-selectivity in the A2 variant. As shown in Figure 2 , two different binding modes were considered for each substrate enantiomer: Mode I is productive for $(R)-\mathbf{4}$, whereas Mode II, is productive for $(S)-4$. When initiating simulations of the Michaelis complex of wild-type $\mathrm{ADH}-\mathrm{A}$ with $(R)-4$ bound in the initially productive Mode I, in which the hydride group being transferred is directed toward the C-4 atom of the nicotinamide group of $\mathrm{NAD}^{+}$, the structure rapidly adjusts to allow the substrate to occupy the cavity formed by the side chains of residues F43, Y54, Y294, F281*, and F282* (Figure $6 \mathrm{~A})$. This results in a nonproductive conformation of the substrate, with the $\alpha$-hydride pointing away from the $\mathrm{NAD}^{+}$ cofactor. In contrast, in the corresponding simulations of the A2 variant, the absence of the bulky indole W295 side chain removes the steric clash that pushes the substrate into a nonproductive conformation in the wild-type enzyme and allows the substrate to remain in a productive conformation throughout the simulation (Figure 6B). In simulations of this variant, a distance of $<3 \AA$ is maintained between the $\alpha$-hydride atom of the substrate and the $\mathrm{C}-4$ atom of nicotinamide ring of the substrate (Figure 7A and Table S6), and the benzene ring of the substrate occupies the position formerly occupied by the indole ring of the W295 side chain (Figure 6B). These results are therefore in agreement with experimental data which indicates a 20 -fold higher value of $k_{\text {cat }}$ toward (R)-4 in the A2 variant than in the wild-type enzyme (Table S5).

We note that, for completeness, we also performed simulations starting from the Michaelis complexes between wild-type $\mathrm{ADH}-\mathrm{A}$ and the $\mathrm{A} 2$ variant and compound $(R)-4$ bound in the nonproductive binding mode, Mode II (Figures $2 \mathrm{~B}$ and $S 7 A, B)$. In both enzymes, the substrate maintained a nonproductive binding mode for the duration of the simulation time, with an average distance of $\sim 5 \AA$ between the $\alpha$-hydride atom of the substrate and the C-4 atom of nicotinamide ring of the substrate (Figure 7B and Table S6).

Finally, corresponding simulations were also performed of the $(S)$-enantiomer of compound $\mathbf{4}$ in complex with wild-type $\mathrm{ADH}-\mathrm{A}$ and the $\mathrm{A} 2$ variant. In this case, we initiated our simulations from the productive Mode II conformation of the substrate (Figure 2D). In the case of the wild-type enzyme, the structure remains stable throughout the simulations, with the substrate aligned in a favorable orientation for hydride transfer (Figure 6C), maintaining a distance of $<3 \AA$ between the $\alpha$ hydride of the substrate and the $\mathrm{C}-4$ atom of the $\mathrm{NAD}^{+}$cofactor (Figure 7D and Table S6). This is in agreement with the $(S)$ selectivity of the wild-type enzyme toward this substrate (Table $\mathrm{S} 5$ ). In contrast, in simulations of the A2 variant, despite starting simulations from a stable, productive conformation (Mode II), $(S)-4$ becomes extremely unstable in the active site, as indicated by average distances of $4.1 \pm 1.4 \AA$ between the $\alpha$-hydride of the substrate and the $\mathrm{C}-4$ atom of the $\mathrm{NAD}^{+}$cofactor, as shown in Figure 7D and Table S6. Once again, for completeness, we also initiated trajectories from the nonproductive binding mode for this enantiomer, Mode I (Figures 2C and S7C,D), and we observed that for the wild-type enzyme, the side chain of the substrate flips to fill in the cavity formed by the side chains of residues F43, Y54, Y294, F281* and F282* (Figure S7C), adopting again a productive and stable conformation, with a distance between the $\alpha$-hydride of the substrate and the C-4 atom of the $\mathrm{NAD}^{+}$cofactor of $<3 \AA$ (Figure $7 \mathrm{C}$ and Table S6). On the other hand, for the A2 variant, the absence of the bulky indole side chain of residue W295 allows the substrate to stay stable in a nonproductive conformation (Figure S7D) along the simulated time, maintaining a distance of around $5 \AA$ between $\alpha$ hydride of $(S)-4$ and the C-4 atom of the cofactor (Figure $7 \mathrm{C}$ and Table S6). These results are consequently in agreement with the experimental data showing a 10 -fold higher value of $k_{\text {cat }}$ 
toward $(S)-4$ in the wild-type enzyme than in the $\mathrm{A} 2$ variant (Table S5).

In order to further explore the origin of these variations in substrate stability during our simulations, we performed further analysis of the joint distribution of the $d_{1}$ and $d_{2}$ dihedral angles of $(R)$ - and (S)-4 (Figure S8) during our simulations, in the respective preferred binding modes (Mode I for $(R)-4$ and Mode II for (S)-4) (Figure 8). Shown here are also representative structures, obtained by performing clustering analysis on our simulations using a hierarchical clustering algorithm based on the RMSD of the substrate, as well as side chain residues Y294 and W295, using an epsilon of 2.0, corresponding to different highly populated regions on these plots. As can be seen from this data, in all cases, the truncation of the W295 side chain to alanine in the A2 variant, and the associated increase in space in the active site cavity, expands the conformational space available to the substrate. In the case of (R)-4, despite this increased conformational diversity, the alignment of this enantiomer in the active site allows for the formation of $\pi$-stacking interactions with the side chains of F43, $\mathrm{F} 281^{*}$, and $\mathrm{F} 282 *$ in the A2 variant (Figure 6), which stabilizes the substrate in the active site and allows it to maintain a catalytically favorable conformation in our simulations. In contrast, in the case of $(S)-4$, these interactions are inaccessible to the substrate, and instead the substrate becomes highly "floppy" upon introduction of the W295A substitution in the A2 variant, losing the stable productive conformation observed in the wild-type enzymes (Figures 6-8 and S7). Therefore, subtle changes in the volume and shape of the active site cavity lead to alterations in the conformational ensembles for the two enantiomers that reverse the selectivity of the enzyme toward favoring the $(R)$-enantiomer of the substrate when the W295A substitution is introduced. We predict a similar rationale for changes in selectivity in other variants carrying this amino acid substitution.

\section{CONCLUSIONS}

In this work, we have targeted a cohort of in vitro evolved alcohol dehydrogenases for a systematic study of structure-dynamicsfunction relationships in closely related enzyme variants. Such comparative enzymology of both natural and/or artificially developed enzymes is a powerful tool that provides unique possibilities for the assessment of the evolution of possibly new or undetected functions, distinct from the properties that were targeted in the original laboratory evolution efforts. We have identified residue W295 as an important structural determinant for stereoselectivity in the oxidation of 1-methyl substituted arylated alcohol. The W295A substitution also allows for significant improvements of the catalytic activities of these variants toward 1-phenyl-1-butanol, where the $(R)$-enantiomer is not accepted at all as a substrate by the wild-type enzyme. Through molecular dynamics simulations, we were able to rationalize the observed alterations in stereoselectivity caused by the same active-site substitution and also provide information regarding alternative substrate binding modes connected to the resulting structural remodeling of the active sites in a W295A containing mutant. In order to achieve a full switch in the enantiopurity in the alcohol products of ketone reduction, further structural changes will be required that steer the substrate binding for hydride addition to the si face only, thus forming the $(R)$-alcohols.

Furthermore, to the best of our knowledge, we report herein the first experimental observation of (apparent) interdepend- ency between substrate/product and cofactor in the ternary complex that directly affects the $\mathrm{NADH}$ dissociation rates (allowing them to become faster), as compared with dissociation from the binary enzyme-NADH complex. This indicates that the structure and dynamics of the microenvironment that is relevant during catalysis, that is, during the assayed steady states, are not captured in binding studies only involving enzyme and cofactor and thus that this more comprehensive analysis is critical as a cornerstone to guide future design effort.

\section{ASSOCIATED CONTENT}

\section{SI Supporting Information}

The Supporting Information is available free of charge at https://pubs.acs.org/doi/10.1021/acscatal.0c01654.

Additional kinetic measurements and simulation data (force field parameters for nonstandard ligands an additional analysis) (PDF)

\section{AUTHOR INFORMATION}

\section{Corresponding Authors}

Mikael Widersten - Department of Chemistry - BMC, Uppsala University, SE-751 23 Uppsala, Sweden; (1) orcid.org/00000002-3203-3793; Email: mikael.widersten@kemi.uu.se

Shina C. L. Kamerlin - Department of Chemistry - BMC, Uppsala University, SE-751 23 Uppsala, Sweden; 이이.org/ 0000-0002-3190-1173; Email: lynn.kamerlin@kemi.uu.se

\section{Authors}

Thilak Reddy Enugala - Department of Chemistry - BMC, Uppsala University, SE-751 23 Uppsala, Sweden; 이이.org/ 0000-0001-5915-1514

Marina Corbella Morató - Department of Chemistry - BMC, Uppsala University, SE-751 23 Uppsala, Sweden

Complete contact information is available at: https://pubs.acs.org/10.1021/acscatal.0c01654

\section{Author Contributions}

TRE, MW, SCLK and MCM designed experiments. TRE and MCM performed experiments. All authors analyzed data. The manuscript was written through contributions of all authors. All authors have given approval to the final version of the manuscript.

\section{Notes}

The authors declare no competing financial interest.

\section{ACKNOWLEDGMENTS}

The contributions of Carl Ottosson to the work is gratefully acknowledged. We are grateful for the computer resources and assistance provided by the Barcelona Supercomputing Center Centro Nacional de Supercomputación. The work was supported by Stiftelsen Olle Engkvist Byggmästare (MW), The Carl Trygger Foundation (MW), The OE \& Edla Johansson Foundation (MW), and the Knut and Alice Wallenberg Foundation (Wallenberg Academy Fellowship 2018.0140). The simulations were performed on resources provided by the Swedish National Infrastructure for Computing (SNIC).

\section{REFERENCES}

(1) Currin, A.; Swainston, N.; Day, P. J.; Kell, D. B. Synthetic Biology for the Directed evolution of Protein Biocatalysts: Navigating Sequence Space Intelligently. Chem. Soc. Rev. 2015, 44, 1172-1239. 
(2) Packer, M. S.; Liu, D. R. Methods for the Directed Evolution of Proteins. Nat. Rev. Genet. 2015, 16, 379-394.

(3) Röthlisberger, D.; Khersonsky, O.; Wollacott, A. M.; Jiang, L.; DeChancie, J.; Betker, J.; Gallaher, J. L.; Althoff, E. A.; Zanghellini, A.; Dym, O.; Albeck, S.; Houk, K. N.; Tawfik, D. S.; Baker, D. Kemp Elimination Catalysts by Computational Enzyme Design. Nature 2008, 453, 190-195.

(4) Renata, H.; Wang, Z. J.; Arnold, F. H. Expanding the Enzyme Universe: Accessing Non-Natural Reactions by Mechanism-Guided Directed Evolution. Angew. Chem., Int. Ed. 2015, 54, 3351-3367.

(5) Obexer, R.; Godina, A.; Garrabou, X.; Mittl, P. R. E.; Baker, D.; Griffiths, A. D.; Hilvert, D. Emergence of a Catalytic Tetrad During Evolution of a Highly Active Artificial Aldolase. Nat. Chem. 2017, 9, $50-56$.

(6) Brandenberg, O. F.; Fasan, R.; Arnold, F. H. Exploiting and Engineering Hemoproteins for Abiological Carbene and Nitrene Transfer Reactions. Curr. Opin. Biotechnol. 2017, 47, 102-111.

(7) Turner, N. J. Directed Evolution Drives the Next Generation of Biocatalysts. Nat. Chem. Biol. 2009, 5, 567-573.

(8) Savile, C. K.; Janey, J. M.; Mundorff, E. C.; Moore, J. C.; Tam, S.; Jarvis, W. R.; Colbeck, J. C.; Krebber, A.; Fleitz, F. J.; Brands, J.; Devine, P. N.; Huisman, G. W.; Hughes, G. J. Biocatalytic Asymmetric Synthesis of Chiral Amines from Ketones Applied to Sitagliptin Manufacture. Science 2010, 329, 305-309.

(9) Reetz, M. T. Laboratory Evolution of Stereoselective Enzymes: A Prolific Source of Catalysts for Asymmetric Reactions. Angew. Chem., Int. Ed. 2011, 50, 138-174.

(10) Bornscheuer, U. T.; Huisman, G. W.; Kazlauskas, R. J.; Lutz, S.; Moore, J. C.; Robins, K. Engineering the Third Wave of Biocatalysis. Nature 2012, 485, 185-194.

(11) Tinberg, C. E.; Khare, S. D.; Dou, J.; Doyle, L.; Nelson, J. W.; Schena, A.; Jankowski, W.; Kalodimos, C. G.; Johnsson, K.; Stoddard, B. L.; Baker, D. Computational Design of Ligand-Binding Proteins With High Affinity and Selectivity. Nature 2013, 501, 212-216.

(12) Ring, A. M.; Manglik, A.; Kruse, A. C.; Enos, M. D.; Weis, W. I.; Garcia, K. C.; Kobilka, B. K. Adrenaline-Activated Structure of $\beta_{2^{-}}$ Adrenoceptor Stabilized by an Engineered Nanobody. Nature 2013, 502, 575-579.

(13) Ohno, S. The Rate of Evolution and the Importance of Isolation. Evolution by Gene Duplication; Springer: Berlin, Heidelberg, Germany, 1970; pp 55-58.

(14) Force, A.; Lynch, M.; Pickett, F. B.; Amores, A.; Yan, Y.; Postlethwait, J. Preservation of Duplicate Genes by Complementary, Degenerative Mutations. Genetics 1999, 151, 1531-1545.

(15) Khersonsky, O.; Roodveldt, C.; Tawfik, D. S. Enzyme Promiscuity: Evolutionary and Mechanistic Aspects. Curr. Opin. Chem. Biol. 2006, 10, 498-508.

(16) Hult, K.; Berglund, P. Enzyme Promiscuity: Mechanism and Applications. Trends Biotechnol. 2007, 25, 231-238.

(17) Poelarends, G. J.; Veetil, V. P.; Whitman, C. P. The Chemical Versatility of the $\beta-\alpha-\beta$ Fold: Catalytic Promiscuity and Divergent Evolution in the Tautomerase Superfamily. Cell. Mol. Life Sci. 2008, 65, 3606-3618.

(18) Babtie, A.; Tokuriki, N.; Hollfelder, F. What Makes an Enzyme Promiscuous? Curr. Opin. Chem. Biol. 2010, 14, 200-207.

(19) Khersonsky, O.; Tawfik, D. S. Enzyme Promiscuity: A Mechanistic and Evolutionary Perspective. Annu. Rev. Biochem. 2010, $79,471-505$.

(20) Svedendahl Humble, M.; Berglund, P. Biocatalytic Promiscuity. Eur. J. Org. Chem. 2011, 2011, 3391-3401.

(21) Copley, S. D. An Evolutionary Biochemist's Perspective on Promiscuity. Trends Biochem. Sci. 2015, 40, 72-78.

(22) Pabis, A.; Duarte, F.; Kamerlin, S. C. L. Promiscuity in the Enzymatic Catalysis of Phosphate and Sulfate Transfer. Biochemistry 2016, 55, 3061-3081.

(23) Kaltenbach, M.; Burke, J. R.; Dindo, M.; Pabis, A.; Munsberg, F. S.; Rabin, A.; Kamerlin, S. C. L.; Noel, J. P.; Tawfik, D. S. Evolution of Chalcone Isomerase from a Noncatalytic Ancestor. Nat. Chem. Biol. 2018, 14, 548-555.
(24) Matsuda, T.; Yamanaka, R.; Nakamura, K. Recent Progress in Biocatalysis for Asymmetric Oxidation and Reduction. Tetrahedron: Asymmetry 2009, 20, 513-557.

(25) Zheng, Y.-G.; Yin, H.-H.; Yu, D.-F.; Chen, X.; Tang, X.-L.; Zhang, X.-J.; Xue, Y.-P.; Wang, Y.-J.; Liu, Z.-Q. Recent Advances in Biotechnological Applications of Alcohol Dehydrogenases. Appl. Microbiol. Biotechnol. 2017, 101, 987-1001.

(26) Schrittwieser, J. H.; Velikogne, S.; Hall, M.; Kroutil, W. Artificial Biocatalytic Linear Cascades for Preparation of Organic Molecules. Chem. Rev. 2018, 118, 270-348.

(27) Adlercreutz, P. Cofactor Regeneration in Biocatalysis in Organic Media. Biocatal. Biotransform. 1996, 14, 1-30.

(28) Kroutil, W.; Mang, H.; Edegger, K.; Faber, K. Recent Advances in the Biocatalytic Reduction of Ketones and Oxidation of sec-Alcohols. Curr. Opin. Chem. Biol. 2004, 8, 120-126.

(29) Pival, S. L.; Klimacek, M.; Nidetzky, B. Novel Chemo-Enzymatic Mimic of Hydrogen Peroxide-Forming NAD(P)H Oxidase for Efficient Regeneration of $\mathrm{NAD}^{+}$and $\mathrm{NADP}^{+}$. Adv. Synth. Catal. 2008, 350, $2305-2312$

(30) Voss, C. V.; Gruber, C. G.; Faber, K.; Knaus, T.; Macheroux, P.; Kroutil, W. Orchestration of Concurrent Oxidation and Reduction Cycles for Stereoinversion and Deracemisation of sec-Alcohols. J. Am. Chem. Soc. 2008, 130, 13969-13972.

(31) Hummel, W.; Gröger, H. Strategies for Regeneration of Nicotinamide Coenzymes Emphasizing Self-Sufficient Closed-Loop Recycling Systems. J. Biotechnol. 2014, 191, 22-31.

(32) Ngo, T. A.; Nakata, E.; Saimura, M.; Morii, T. Spatially Organized Enzymes Drive Cofactor-Coupled Cascade Reactions. J. Am. Chem. Soc. 2016, 138, 3012-3021.

(33) Angelastro, A.; Dawson, W. M.; Luk, L. Y. P.; Allemann, R. K. A Versatile Disulfide-Driven Recycling System for $\mathrm{NADP}^{+}$with High Cofactor Turnover Number. ACS Catal. 2017, 7, 1025-1029.

(34) Stampfer, W.; Kosjek, B.; Moitzi, C.; Kroutil, W.; Faber, K. Biocatalytic Asymmetric Hydrogen Transfer. Angew. Chem., Int. Ed. 2002, 41, 1014-1017.

(35) Stampfer, W.; Kosjek, B.; Faber, K.; Kroutil, W. Biocatalytic Asymmetric Hydrogen Transfer Employing Rhodococcus ruber DSM 44541. J. Org. Chem. 2003, 68, 402-406.

(36) Kosjek, B.; Stampfer, W.; Pogorevc, M.; Goessler, W.; Faber, K.; Kroutil, W. Purification and Characterization of a Chemotolerant Alcohol Dehydrogenase Applicable to Coupled Redox Reactions. Biotechnol. Bioeng. 2004, 86, 55-62.

(37) Hamnevik, E.; Blikstad, C.; Norrehed, S.; Widersten, M. Kinetic Characterization of Rhodococcus ruber DSM 44541 Alcohol Dehydrogenase A. J. Mol. Catal. B: Enzym. 2014, 99, 68-78.

(38) Hamnevik, E.; Enugala, T. R.; Maurer, D.; Ntuku, S.; Oliveira, A.; Dobritzsch, D.; Widersten, M. Relaxation of Nonproductive Binding and Increased Rate of Coenzyme Release in an Alcohol Dehydrogenase Increases Turnover with a Nonpreferred Alcohol Enantiomer. FEBS J. 2017, 284, 3895-3914.

(39) Maurer, D.; Enugala, T. R.; Hamnevik, E.; Bauer, P.; Lüking, M.; Petrovic, D.; Hillier, H.; Kamerlin, S. C. L.; Dobritzsch, D.; Widersten, M. Stereo- and Regioselectivity in Catalyzed Transformation of a 1,2Disubstituted Vicinal Diol and the Corresponding Diketone by Wild Type and Laboratory Evolved Alcohol Dehydrogenases. ACS Catal. 2018, 8, 7526-7538.

(40) Hamnevik, E.; Maurer, D.; Enugala, T. R.; Chu, T.; Löfgren, R.; Dobritzsch, D.; Widersten, M. Directed Evolution of Alcohol Dehydrogenase for Improved Stereoselective Redox Transformations of 1-Phenylethane-1,2-diol and Its Corresponding Acyloin. Biochemistry 2018, 57, 1059-1062.

(41) Protein libraries were constructed and selected as described by Manfred Reetz and coworkers Reetz, M. T.; Wang, L.-W.; Bocola, M. Directed Evolution of Enantioselective Enzymes: Iterative Cycles of CASTing for Probing Protein-Sequence Space. Angew. Chem., Int. Ed. 2006, 45, 1236-1241. Details are provided in refs 38-40.

(42) Karabec, M.; Łyskowski, A.; Tauber, K. C.; Steinkellner, G.; Kroutil, W.; Grogan, G.; Gruber, K. Structural Insights into Substrate Specificity and Solvent Tolerance in Alcohol Dehydrogenase ADH-'A' 
from Rhodococcus ruber DSM 44541. Chem. Commun. 2010, 46, 63146316.

(43) The PyMOL Molecular Graphics System, Version 2.1; Schrödinger, LLC, 2018.

(44) Keinan, E.; Hafeli, E. K.; Seth, K. K.; Lamed, R. Thermostable Enzymes in Organic Synthesis. 2.1 Asymmetric Reduction of Ketones with Alcohol Dehydrogenase from Thermoanaerobium brockii. J. Am. Chem. Soc. 1986, 108, 162-169.

(45) Tian, W.; Chen, C.; Lei, X.; Zhao, J.; Liang, J. CASTp 3.0: Computed Atlas of Surface Topography of Proteins. Nucleic Acids Res. 2018, 46, W363-W367.

(46) Michaelis, L.; Menten, M. L. Kinetik der Invertinwirkung. Biochem. Zeitung 1913, 49, 333-369.

(47) Hill, A. V. The Combinations of Haemoglobin with Oxygen and with Carbon Monoxide. I. Biochem. J. 1913, 7, 471-480.

(48) Olsson, M. H. M.; Søndergaard, C. R.; Rostkowski, M.; Jensen, J. H. PROPKA3: Consistent Treatment of Internal and Surface Residues in Empirical $\mathrm{pK}_{\mathrm{a}}$ Predictions. J. Chem. Theory Comput. 2011, 7, 525537.

(49) Case, D. A.; Ben-Shalom, I. Y.; Brozell, S. R.; Cerutti, D. S.; Cheatham, T. E., III; Cruzeiro, V. W. D.; Darden, T. A.; Duke, R. E.; Gilson, M. K.; Gohlke, H.; Goetz, A. W.; Greene, D.; Harris, R.; Homeyer, N.; IZadi, S.; Kovalenko, A.; Kurtzman, T.; Lee, T. S.; LeGrand, S.; Li, P.; Lin, C.; Liu, J.; Luchko, T.; Luo, R.; Mermelstein, D. J.; Merz, K. M.; Miao, Y.; Monard, G.; Nguyen, C.; Nguyen, H.; Omelyan, I.; Onufriev, A.; Pan, F.; Qi, R.; Roe, D. R.; Roitberg, A.; Schott-Verdugo, S.; Shen, J.; Simmerling, C. L.; Smith, J.; SalomonFerrer, R.; Swails, J.; Walker, R. C.; Wang, J.; Wei, H.; Wolf, R. M.; Wu, X.; Xiao, L.; York, D. M.; Kollman, P. A. AMBER 2018; University of California: San Francisco, 2018.

(50) Maier, J. A.; Martinez, C.; Kasavajhala, K.; Wickstrom, L.; Hauser, K. E.; Simmerling, C. Ff14SB: Improving the Accuracy of Protein Side Chain and Backbone Parameters from FF99SB. J. Chem. Theory Comput. 2015, 11, 3696-3713.

(51) Wang, J.; Wang, W.; Kollman, P. A.; Case, D. A. Automatic Atom Type and Bond Type Perception in Molecular Mechanical Calculations. J. Mol. Graphics Modell. 2006, 25, 247-260.

(52) Wang, J. M.; Wolf, R. M.; Caldwell, J. W.; Kollman, P. A.; Case, D. A. Development and Testing of a General Amber Force Field. J. Comput. Chem. 2004, 25, 1157-1174.

(53) Frisch, M. J.; Trucks, G. W.; Schlegel, H. B.; Scuseria, G. E.; Robb, M. A.; Cheeseman, J. R.; Scalmani, G.; Barone, V.; Mennucci, B.; Petersson, G. A.; Nakatsuji, H.; Caricato, M.; Li, X.; Hratchian, H. P.; Izmaylov, A. F.; Bloino, J.; Zheng, G.; Sonnenberg, J. L.; Hada, M.; Ehara, M.; Toyota, K.; Fukuda, R.; Hasegawa, J.; Ishida, M.; Nakajima, T.; Honda, Y.; Kitao, O.; Nakai, H.; Vreven, T.; Montgomery, J. A., Jr.; Peralta, J. E.; Ogliaro, F.; Bearpark, M.; Heyd, J. J.; Brothers, E.; Kudin, K. N.; Staroverov, V. N.; Kobayashi, R.; Normand, J.; Raghavachari, K.; Rendell, A.; Burant, J. C.; Iyengar, S. S.; Tomasi, J.; Cossi, M.; Rega, N.; Millam, J. M.; Klene, M.; Knox, J. E.; Cross, J. B.; Bakken, V.; Adamo, C.; Jaramillo, J.; Gomperts, R.; Stratmann, R. E.; Yazyev, O.; Austin, A. J.; Cammi, R.; Pomelli, C.; Ochterski, J. W.; Martin, R. L.; Morokuma, K.; Zakrzewski, V. G.; Voth, G. A.; Salvador, P.; Dannenberg, J. J.; Dapprich, S.; Daniels, A. D.; Farkas, Ö.; Foresman, J. B.; Ortiz, J. V.; Cioslowski, J.; Fox, D. J. Gaussian 09, Revision D.01; Gaussian, Inc., Wallingford CT, 2016.

(54) Cieplak, P.; Cornell, W. D.; Bayly, C.; Kollman, P. A. Application of the Multimolecule and Multiconformational RESP Methodology to Biopolymers: Charge Derivation for DNA, RNA, and Proteins. J. Comput. Chem. 1995, 16, 1357-1377.

(55) Pavelites, J. J.; Gao, J.; Bash, P. A.; Mackerell, A. D. A Molecular Mechanics Force Field for NAD+ NADH, and the Pyrophosphate Groups of Nucleotides. J. Comput. Chem. 1997, 18, 221-239.

(56) Walker, R. C.; de Souza, M. M.; Mercer, I. P.; Gould, I. R.; Klug, D. R. Large and Fast Relaxations Inside a Protein: Calculation and Measurement of Reorganization Energies in Alcohol Dehydrogenase. J. Phys. Chem. B 2002, 106, 11658-11665.

(57) Peverati, R.; Truhlar, D. G. M11-L: A Local Density Functional That Provides Improved Accuracy for Electrostatic Structure
Calculations in Chemistry and Physics. J. Phys. Chem. Lett. 2012, 3, $117-124$

(58) Scalmani, G.; Frisch, M. J. Continuous Surface Charge Polarizable Continuum Models of Solvation. I. General Formalism. J. Chem. Phys. 2010, 132, 114110.

(59) Jorgensen, W. L.; Chandrasekhar, J.; Madura, J. D.; Impey, R. W.; Klein, M. L. Comparison of Simple Potential Functions for Simulating Liquid Water. J. Chem. Phys. 1983, 79, 926-935.

(60) Ryckaert, J.-P.; Ciccotti, G.; Berendsen, H. J. Numerical Integration of the Cartesian Equations of Motion of a System with Constraints: Molecular Dynamics of $n$-Alkanes. J. Comput. Phys. 1977, 23, 327-341.

(61) Feller, S. E.; Zhang, Y.; Pastor, R. W.; Brooks, B. R. Constant Pressure Molecular Dynamics Simulation: The Langevin Piston Method. J. Chem. Phys. 1995, 103, 4613-4621.

(62) Berendsen, H. J. C.; Postma, J. P. M.; van Gunsteren, W. F.; DiNola, A.; Haak, J. R. Molecular Dynamics with Coupling to an External Bath. J. Chem. Phys. 1984, 81, 3684-3690.

(63) Bornscheuer, U. T.; Kazlauskas, R. J. Catalytic Promiscuity in Biocatalysis: Using Old Enzymes to Form New Bonds and Follow New Pathways. Angew. Chem., Int. Ed. 2004, 43, 6032-6040.

(64) Wang, S.; Nie, Y.; Xu, Y.; Zhang, R.; Ko, T.-P.; Huang, C.-H.; Chan, H.-C.; Guo, R.-T.; Xiao, R. Unconserved Substrate-Binding Sites Direct the Stereoselectivity of Medium-Chain Alcohol Dehydrogenase. Chem. Commun. 2014, 50, 7770-7772.

(65) Ensari, Y.; Dhoke, G. V.; Davari, M. D.; Bocola, M.; Ruff, A. J.; Schwaneberg, U. Inversion of cpADH5 Enantiopreference and Altered Chain Length Specificity for Methyl 3-Hydroxyalkanoates. Chem. - Eur. J. 2017, 23, 12636-12645.

(66) Li, H.; Zhu, D.; Hua, L.; Biehl, E. R. Enantioselective Reduction of Diaryl Ketones Catalyzed by a Carbonyl Reductase from Sporobolomyces salmonicolor and its Mutant Enzymes. Adv. Synth. Catal. 2009, 351, 583-588.

(67) Musa, M. M.; Lott, N.; Laivenieks, M.; Watanabe, L.; Vieille, C.; Phillips, R. S. A Single Point Mutation Reverses the Enantiopreference of Thermoanaerobacter ethanolicus Secondary Alcohol Dehydrogenase. ChemCatChem 2009, 1, 89-93.

(68) Agudo, R.; Roiban, G.-D.; Reetz, M. T. Induced Axial Chirality in Biocatalytic Asymmetric Ketone Reduction. J. Am. Chem. Soc. 2013, $135,1665-1668$.

(69) Korkhin, Y.; Kalb, A. J.; Peretz, M.; Bogin, O.; Burstein, Y.; Frolow, F. NADP-dependent Bacterial Alcohol Dehydrogenases: Crystal Structure, Cofactor-binding and Cofactor Specificity of the $\mathrm{ADHs}$ of Clostridium beijerinckii and Thermoanaerobacter brockii. J. Mol. Biol. 1998, 268, 967-981.

(70) Maria-Solano, M. A.; Romero-Rivera, A.; Osuna, S. Exploring the Reversal of Enantioselectivity on a Zinc-Dependent Alcohol Dehydrogenase. Org. Biomol. Chem. 2017, 15, 4122-4129.

(71) Plapp, B. V. Conformational Changes and Catalysis by Alcohol Dehydrogenase. Arch. Biochem. Biophys. 2010, 493, 3-12.

(72) Sekhar, V. C.; Plapp, B. V. Rate Constants for a Mechanism Including Intermediates in the Interconversion of Ternary Complexes by Horse Liver Alcohol Dehydrogenase. Biochemistry 1990, 29, 42894295. 